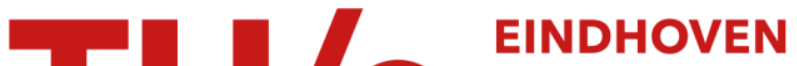 UNIVERSITY OF TECHNOLOGY
}

\section{Experimental investigation of transients-induced fluid-structure interaction in a pipeline with multiple-axial supports}

\section{Citation for published version (APA):}

Keramat, A., Fathi-Moghadam, M., Zanganeh, R., Rahmanshahi, M., Tijsseling, A. S., \& Jabbari, E. (2020). Experimental investigation of transients-induced fluid-structure interaction in a pipeline with multiple-axial supports. Journal of Fluids and Structures, 93, [102848]. https://doi.org/10.1016/j.jfluidstructs.2019.102848

\section{Document license:}

TAVERNE

DOI:

10.1016/j.jfluidstructs.2019.102848

Document status and date:

Published: 01/02/2020

\section{Document Version:}

Publisher's PDF, also known as Version of Record (includes final page, issue and volume numbers)

\section{Please check the document version of this publication:}

- A submitted manuscript is the version of the article upon submission and before peer-review. There can be important differences between the submitted version and the official published version of record. People interested in the research are advised to contact the author for the final version of the publication, or visit the $\mathrm{DOI}$ to the publisher's website.

- The final author version and the galley proof are versions of the publication after peer review.

- The final published version features the final layout of the paper including the volume, issue and page numbers.

Link to publication

\section{General rights}

Copyright and moral rights for the publications made accessible in the public portal are retained by the authors and/or other copyright owners and it is a condition of accessing publications that users recognise and abide by the legal requirements associated with these rights.

- Users may download and print one copy of any publication from the public portal for the purpose of private study or research.

- You may not further distribute the material or use it for any profit-making activity or commercial gain

- You may freely distribute the URL identifying the publication in the public portal.

If the publication is distributed under the terms of Article 25fa of the Dutch Copyright Act, indicated by the "Taverne" license above, please follow below link for the End User Agreement:

www.tue.nl/taverne

Take down policy

If you believe that this document breaches copyright please contact us at:

openaccess@tue.nl

providing details and we will investigate your claim. 


\title{
Experimental investigation of transients-induced fluid-structure interaction in a pipeline with multiple-axial supports
}

\author{
Alireza Keramat ${ }^{a, *}$, Manoochehr Fathi-Moghadam ${ }^{\mathrm{b}}$, Roohollah Zanganeh ${ }^{\mathrm{c}}$, \\ Mostafa Rahmanshahi ${ }^{\mathrm{d}}$, Arris S. Tijsseling ${ }^{\mathrm{e}}$, Ebrahim Jabbari ${ }^{\mathrm{c}}$ \\ a Civil Engineering department, Jundi-Shapur University of Technology, Dezful, Iran \\ ${ }^{\mathrm{b}}$ Department of Hydraulic Structures, Shahid Chamran University of Ahvaz, Ahvaz, Iran \\ ${ }^{\mathrm{c}}$ Department of Civil Engineering, Iran University of Science and Technology, Tehran, Iran \\ ${ }^{\mathrm{d}}$ Department of Water Science Engineering, Shahid Chamran University of Ahvaz, Ahvaz, Iran \\ e Department of Mathematics and Computer Science, Eindhoven University of Technology, Eindhoven, The Netherlands
}

\section{A R T I C L E I N F O}

\section{Article history:}

Received 20 June 2019

Received in revised form 15 December 2019

Accepted 17 December 2019

Available online 30 December 2019

\section{Keywords:}

Waterhammer

Fluid-structure interaction

Pipeline supports

Frequency spectrum

\begin{abstract}
A B S T R A C T
Fluid-Structure Interaction (FSI) in pipes can significantly affect pressure fluctuations during water hammer event. In transmission pipelines, anchors with axial stops have an important role in the waterhammer-induced FSI as they can suppress or allow the propagation of additional stress waves in the pipe wall. More specifically, a reduction in the number of axial stops and/or their stiffness causes significant oscillations in the observed pressure signal due to the enhancement of Poisson's coupling. To confirm these physical arguments, this research conducts experimental investigations and then processes the collected pressure signals. The laboratory tests were run on an anchored pipeline with multiple axial supports which some of them removed at some sections to emerge Poisson's coupling. The collected pressure signals are analyzed in the time and frequency domain in order to decipher fluctuations that stem from Poisson coupling and other anchors effects. The analysis of the laboratory data reveals that the pattern of the time signals of pressure is primarily affected by the stiffness and location of the supports. Likewise, the properties of structural boundaries characterize the frequency spectrum of the transient pressures, which is manifested by altering the amplitudes corresponding to dominant frequencies of the system. The study is of particular importance in practice of transient based defect detections and pipe system design.
\end{abstract}

(c) 2019 Elsevier Ltd. All rights reserved.

\section{Introduction}

Transient pressures in pipelines generate axial stresses and strains in the pipe-wall by means of the Poisson effect and unbalanced forces at junctions. The hoop strain caused by the pressure of contained fluid generates an axial strain due to Poisson contraction (Tijsseling, 2007). In case the produced axial stresses and strains are large enough to excite and thus move the pipe, their impact on the transient pressure wave is important so that simulations need to take into

\footnotetext{
* Corresponding author.

E-mail addresses: keramat.alireza@gmail.com, keramat@jsu.ac.ir (A. Keramat), mfathi@scu.ac.ir (M. Fathi-Moghadam), r_zanganeh@civileng.iust.ac.ir (R. Zanganeh), mostafarahmanshahi@gmail.com (M. Rahmanshahi), a.s.tijsseling@tue.nl (A.S. Tijsseling), jabbari@iust.ac.ir (E. Jabbari).
} 
account fluid-structure interaction (FSI). The FSI-induced pressure fluctuations are of particular importance in practice of transient-based defect-detection methods, because they resemble the signatures of actual leaks, blockages or other deficiencies in the pipe system (see e.g. the experimental results in Keramat et al., 2019; Wang et al., 2019a,b); hence simulating FSI may lead to a more reliable defect identification.

The geometry of the pipe system and fluid and structural parameters quantify the dynamic characteristics of fluid and pipes and consequently the significance of FSI. As pointed out in the notable review paper by Li et al. (2015), among the 187 reviewed references, only 32 literatures contain laboratory studies and only 7 take the practical application of pipe systems into consideration. Accordingly, the literature on theoretical models and methods of FSI is well-developed but indeed more efforts are needed to bridge the gap between theoretical research and industrial practice.

In the routine reservoir-pipe-valve systems, FSI occurs mainly due to the Poisson effect and the vibration of the downstream valve. These mechanical processes excite the pipe vibration modes, which correspond to axial wave propagation in the pipe wall in the most simplified FSI models. Restrained anchors are mostly used in pipeline facilities to restrict undesired system vibrations so that the piping structure remains stable and reliable. Fixed anchors restrict against axial movement of the pipe based on their stiffness in the axial direction and they counterbalance the axial stresses of the pipe-wall, which are transmitted to the surrounding ground by means of dry friction (Feeny et al., 1998). The transient pressure is a function of structural constrains located throughout the pipeline. If the pipeline is fully restrained along its entire length, then all coupling mechanisms (Poisson, friction, and junction) are eliminated, and likewise, if hypothetically the pipe material has zero Poisson's ratio, then the Poisson coupling does not appear. Nevertheless, these assumptions are usually not valid due to lack or deterioration of pipe supports and a non-zero Poisson's ratio.

Lavooij and Tijsseling (1991) investigated the effect of the inertia of a downstream moving valve during a waterhammer event. Heinsbroek and Tijsseling (1994) assessed the influence of the pipe-supports' stiffness in an elastic pipe, and found that the rigidity of the bend's support affects waterhammer pressure amplitude and phase, and recommended more detailed analyses. Tijsseling and Vardy (1996) examined the interacting effect of pipe racks on waterhammer waves including the dry friction occurring between the pipe-wall and the rack elements. They conducted accurate computations which were compared with measurements. Finally, they provided quantitative criteria to anticipate when dry friction forces are significant during hydraulic transients. Yang et al. (2004) analyzed the effect of rigid constraints in multi-span pipes in the frequency domain, concluding that the junction coupling has a larger effect on the transient wave than the Poisson coupling. However, detailed significance of Poisson coupling due to multiple supports - especially its impact on the frequency spectrum of fluid pressure - was not addressed. Ferras et al. (2017) carried out a set of experimental tests in a straight copper pipe in which rigidly fixed stainless steel clamps were used for the pipe anchoring. The tests precisely represent the effects of movement and dry friction of anchor blocks on transient responses. To assess the axial supports' impact on pressures, a reservoir-pipeline-valve system was closely investigated. The system was initially restrained completely by several anchors along the pipeline and then they were loosened one by one. Lack of conclusions for the natural frequencies of the collected pressure data from the conducted laboratory experiments with various supports arrangements justifies a further study of this kind. Adamkowski et al. (2017) conducted several laboratory experiments to examine the influence of elastic pipe supports on waterhammer. The excitation mechanism in their experiment was direct pipe hitting by a hammer (axially at a closed end) which produces pressure rises similar to valve closure. The results of the experiments demonstrate higher amplitudes at fluid resonant frequencies for supports with lower stiffness due to better energy transfer from pipe structure to the contained fluid. Other studies on FSI and the role of supports are by Lesmez et al. (1990), Kwong and Edge (1998), Diesselhorst et al. (2000), Liu and Li (2011), Henclik (2012), Xu et al. (2014), Zanganeh et al. (2015, 2019), and Henclik (2018). None of these studies discusses the effects of support positions and support stiffness on the frequency spectra of fluid pressures (with FSI) in comparison to frequency spectra of fluid or pipe structure solely (without FSI).

The present research aims at investigating the behavior of a viscoelastic pipeline, which is fixed by regular anchored brackets during waterhammer with modeling FSI. More specifically, the effects of different configurations of anchored supports located along the pipe on the pressure heads, especially in the first-half period, is experimentally probed. The laboratory waterhammer tests were carried out in a polyethylene (PE) pipe for six different anchoring configurations along the pipeline used to control vibrations. Different configurations are made by releasing or anchoring some supports along the pipeline.

\section{Theoretical background}

A concise review on the theory of waterhammer with FSI is provided. One may study a fluid-filled pipe system by its field (domain) properties and by boundary relations. Wave speed is an intrinsic property of the domain (pipe or fluid) which in conjunction with boundary conditions defines natural (resonant) frequencies. Natural frequencies of a fluid-filled pipe system consist of altered resonant frequencies of fluid and pipe separately. Considering FSI mechanisms, Zhang et al. (1999) showed that fluid natural frequencies have their largest deviations around structural natural frequencies.

The different wave speeds in fluid and pipe wall are considered and discussed as the building block towards the understanding of coupled wave propagation. Furthermore, transient waves in a reservoir-pipe-valve model of the laboratory test, as a typical example of an open-closed system, are studied. The resonant frequencies of the system are determined from the governing equations and boundary conditions. 


\subsection{Fluid-structure interaction}

There are three basic kinds of fluid-structure interaction mechanisms (Tijsseling, 1996): Poisson, friction and junction coupling. The first stems from the interaction between the axial motion of the pipe-wall and the pressure in the fluid by means of the Poisson contraction effect. The fluid pressure wave is responsible for circumferential (hoop) stresses and strains, which result in longitudinal stresses and strains propagating in the pipe wall. The speeds of propagation in the solid and fluid are about the classic (uncoupled) celerities:

$$
c_{t}=\sqrt{\frac{E}{\rho_{t}}}
$$

and

$$
c_{f}=\left(\rho_{f}\left(\frac{1}{K}+\left(1-v^{2}\right) \frac{D}{e E}\right)\right)^{-\frac{1}{2}},
$$

in which $E$ is the Young modulus, $\rho_{t}$ is the density of pipe wall material, $K$ and $\rho_{f}$ are the bulk modulus and density of the liquid, $v$ is the Poisson ratio of the pipe wall material, $D$ is the internal pipe diameter and $e$ is the pipe wall thickness. The Poisson interaction between stress and pressure waves is the consequence of the difference between the stress and pressure wave speeds. It can theoretically vanish only when the whole pipeline is restrained from axial movement, which is nearly impossible in practice. Thus, the effects of Poisson coupling cannot be neglected with alternate supports, which is the case in reality, even though being too close.

The weakest FSI mechanism is friction coupling (Wiggert and Tijsseling, 2001; Tijsseling, 1996) which arises from the shear stress between the pipe-wall and the contained fluid. The third mechanism is junction coupling occurring at moving boundaries like bends, T-junctions, ends, valves, etc., which is enhanced in pipes with no or non-rigid supports (Wiggert et al., 1985; Heinsbroek and Tijsseling, 1994; Wiggert and Tijsseling, 2001; Keramat et al., 2012; Henclik, 2012; Zanganeh et al., 2015, 2019; Adamkowski et al., 2017). The junction coupling results from unbalanced local forces caused by change of fluid momentum and/or pressure. The first two mechanisms of FSI coupling are modeled by distinct terms in the governing equations (field property) but the third one, the junction coupling, is modeled herein by boundary conditions.

The FSI phenomenon alters pressure heads and fundamental periods of waterhammer compared to classical hydraulic transient models which also manifests itself in change of resonant frequencies and corresponding amplitudes (Hara, 1988; Tijsseling, 1996; Zhang et al., 1999; Ahmadi and Keramat, 2010; Zanganeh et al., 2015, 2019; Henclik, 2018).

\subsection{Natural frequencies}

To study the vibration characteristics of a fluid-filled pipe system, the interaction mechanisms between the pipe walls and contained fluid have to be taken into account. In this section, the uncoupled natural frequencies of pipe and fluid are expressed. They are utilized to scrutinize the experimental data in the later sections.

Zhang et al. (1999) along with several other researches (Lesmez et al., 1990; Yang et al., 2004; Liu and Li, 2011; Xu et al., 2014) suggest how to anticipate the natural frequencies of the system with FSI from those of an empty pipe and of the contained fluid without FSI. Three sets of natural frequencies corresponding to different waves can be defined: fluid pressure without FSI defined by $f_{f}$, axial vibration of the pipe wall in cases of symmetric (restrained-restrained, v.i. Fig. 1a) and anti-symmetric (restrained-unrestrained, v.i. Fig. 2a) arrangement of supports denoted by $f_{s s}$ and $f_{s a}$, which are (Clough and Penzien, 1993):

$$
f_{f, n}=\frac{(2 n-1) c_{f}}{4 L}, \quad f_{s a, n}=\frac{(2 n-1) c_{t}}{4 L}, \quad f_{s s, n}=\frac{n c_{t}}{2 L}, \quad n=1,2, \ldots
$$

where $L$ is the length of pipe between supports. The natural frequencies in Eq. (3) correspond to a continuous and uniform distribution of mass. An alternative procedure, explained in the following, adopts lumped-mass idealization to limit the number of degrees of freedom and thus simplify the dynamic analysis.

The experimental studies of frequency responses of many systems (e.g. Adamkowski et al., 2017) including the facility in the current research reveal that dominant structural modes of vibration affect the transient pressure responses (Zhang et al., 1999). This means that the influence of pipe vibrations and interaction mechanisms on transient modes of pressure can effectively be studied using the most influential natural frequencies of the pipe wall structure, and these may be modeled by a single or multi-degree of freedom (MDOF) system (Ferras et al., 2017). In reality (industrial pipelines or laboratory experiments) it is hard to assess support performance subject to dynamic forces so that usually a behavior between completely rigid (Fig. 1b) or completely free to move (Fig. 2b, the right support) is assumed. Accordingly, this approach is followed herein to study possible vibrational effects of the pipe structure on the transient pressures. Consider a single-degree-of-freedom (SDOF) structural system in which the axial pipe wall stiffness $E A_{t} / L$ defines the spring, and the added mass of fluid, pipe and other vibrating elements provide the mass $M$. The system then vibrates with one natural mode which for symmetric (Fig. 1b) and anti-symmetric system (Fig. 2b) has the following frequencies:

$$
f_{s s}^{s}=\frac{\omega_{n}}{2 \pi}=\frac{1}{2 \pi} \sqrt{\frac{K}{M}}=\frac{1}{2 \pi} \sqrt{\frac{4 E A_{t}}{L M}}, \quad f_{s a}^{s}=\frac{1}{2 \pi} \sqrt{\frac{2 E A_{t}}{L M}} .
$$


a)

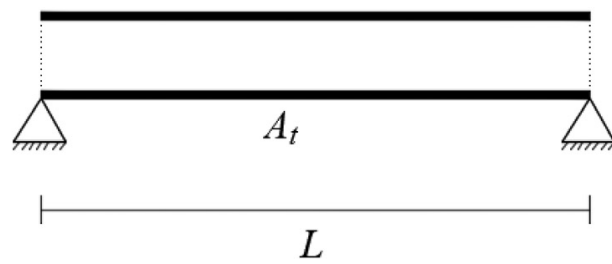

b)

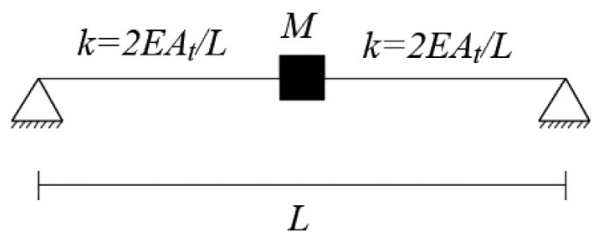

Fig. 1. Symmetric arrangement of pipe supports (restrained-restrained): (a) section of pipe, (b) its single-degree of freedom (SDOF) model for longitudinal vibration.

a)

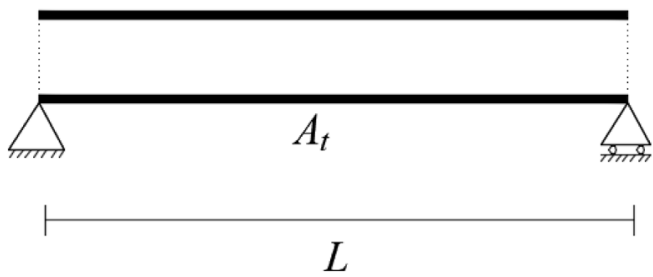

b)

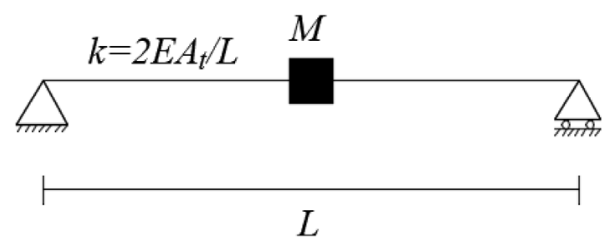

Fig. 2. Anti-symmetric arrangement of pipe supports (restrained-unrestrained): (a) longitudinal cross section of pipe, (b) its Single-degree of freedom (SDOF) model.

where superscript "s" stands for SDOF system. If only the mass of the pipe is involved i.e. $M_{t}=\rho_{t} A_{t} L$, then Eqs. (4) are first approximations for the frequency of the first natural mode given by Eqs. (3).

The system may be modeled with more combinations of mass and springs (MDOF). If damping mechanisms (such as viscous damping and friction) are present in the system, then $\omega_{D}=\omega_{n} \sqrt{1-\xi^{2}}$, in which $\xi<1$ is the damping ratio. For $\xi \leq 0.2$ the damping effect on the natural frequency may be neglected (Clough and Penzien, 1993) and so $\omega_{D} \cong \omega_{n}$ (applied in the experiments of this research).

\subsection{Determination of frequency responses from a time signal}

Transient signals in pipes are usually presented as head variations in time, $H\left(t, z=z_{0}\right)$, where $z_{0}$ represents a specified location of the system. The collected data include discrete time samples of the continuous pressure response of the system indicated by $H\left(t, z=z_{0}\right)=H_{0}+\tilde{H}(t)$, where $H_{0}$ represents the mean component about which the transient response oscillates, and $\tilde{H}(t)$ denotes the zero-mean transient component of pressure. In transient analysis, the mean component is often removed and the remaining transient component can be efficiently converted into the Fourier domain through the discrete Fourier transform. The value of the $n$th data point in the transformed sequence is given as (Lee et al., 2013):

$$
h_{n}=\sum_{k=0}^{N-1} \tilde{H}_{k} \mathrm{e}^{-\mathrm{i} 2 \pi k n / N}, n=0,1, \ldots, N-1
$$

where $N$ is the total number of data points in a sequence of measured pressure heads $\tilde{H}_{k}$, the subscript $k$ indicates the frequency component, $h_{n}$ is the amplitude of the $n$th mode in the spectrum and $\mathrm{i}=\sqrt{-1}$. Eq. (5) is the mathematical representation of the fact that any time signal can be viewed as a sum of $N$ different modes (corresponding to each frequency $k / N$ ) where the amplitude of each mode is $h_{n}$.

The Fourier transform includes a series of numbers that are complex conjugate and symmetric about the maximum frequency in the spectrum (for real signal data). According to the Nyquist-Shannon theory (1949), the highest frequency that is captured in the collected signal is half that of the sampling frequency,

$$
f_{N}=\frac{1}{2 \Delta t}
$$

where $\Delta t$ is sampling time interval in the original signal. If a real signal has frequency content higher than that of the Nyquist frequency, then the collected signal is aliased as a signal with lower bandwidth and the higher frequencies are lost.

Two aspects related to the Nyquist frequency are of great importance in our experimental studies. The first one is that the utilized sensors should be able to capture data with a frequency twice higher than the Nyquist frequency. Secondly, 
Table 1

Specifications of the reservoir-viscoelastic pipeline-valve experiment.

\begin{tabular}{|c|c|c|c|c|c|c|c|c|c|}
\hline \multirow{2}{*}{$\begin{array}{l}\text { Length } \\
(\mathrm{m})\end{array}$} & $\begin{array}{l}\text { Inner diameter } \\
(\mathrm{mm})\end{array}$ & \multirow{2}{*}{$\begin{array}{l}\text { Wall thickness } \\
(\mathrm{mm}) \\
6.5\end{array}$} & \multirow{2}{*}{$\begin{array}{l}\text { Young's modulus } \\
\text { (GPa) } \\
1.20\end{array}$} & Poisson's ratio & \multicolumn{5}{|c|}{$\begin{array}{l}\text { Retardation times } \tau_{k}(\mathrm{~s}) \text { and creep coefficients } \\
J_{k}\left(10^{-10} \mathrm{~Pa}^{-1}\right) \\
\text { Number of } \mathrm{K}-\mathrm{V} \text { elements }=5\end{array}$} \\
\hline & 50.5 & & & 0.46 & $\begin{array}{l}\tau_{1}=0.05 \\
J_{1}=0.76\end{array}$ & $\begin{array}{l}\tau_{2}=0.5 \\
J_{2}=1.37\end{array}$ & $\begin{array}{l}\tau_{3}=1.5 \\
J_{3}=0.66\end{array}$ & $\begin{array}{l}\tau_{4}=5 \\
J_{4}=0.31\end{array}$ & $\begin{array}{l}\tau_{5}=10 \\
J_{5}=0.76\end{array}$ \\
\hline $\begin{array}{l}\text { Flow rate } \\
(1 / s)\end{array}$ & \multicolumn{2}{|c|}{$\begin{array}{l}\text { Closure time of } \\
\text { the valve (ms) }\end{array}$} & $\begin{array}{l}\text { Reservoir } \\
\text { head }(\mathrm{m})\end{array}$ & \multicolumn{2}{|c|}{$\begin{array}{l}c_{f}(v=0) \\
(\mathrm{m} / \mathrm{s})\end{array}$} & \multicolumn{2}{|c|}{$\begin{array}{l}c_{f}(v=0.46) \\
(\mathrm{m} / \mathrm{s})\end{array}$} & \multicolumn{2}{|r|}{$\begin{array}{l}c_{t} \\
(\mathrm{~m} / \mathrm{s})\end{array}$} \\
\hline 1.12 & \multicolumn{2}{|l|}{50} & 46.0 & \multicolumn{2}{|l|}{379} & \multicolumn{2}{|l|}{423} & & 1095 \\
\hline
\end{tabular}

the experiment should be conducted such that the generated signal contains useful information from the system. For example, in typical transient-based-defect-detection methods, the generated signal should be of high enough frequency bandwidth (thus sharp transients) to provide the desired information from the system (Ferrante and Brunone, 2003; Lee et al., 2013, 2015; Gong et al., 2015; Ferrante et al., 2014; Keramat et al., 2018; Keramat and Zanganeh, 2019).

Eq. (5) can efficiently be implemented using the Fast Fourier Transform (FFT) algorithms, which allows for a recursive computation of the required summations (Oppenheim et al., 1983).

\section{Experimental setup}

The experimental facility located at Shahid Chamran University of Ahvaz, Iran, consisted of high-density polyethylene (HDPE) water-filled pipes (SDR11, PE100, and NP16 bar) connected to a pressure vessel. The total length of the pipeline, which is constructed in stacked loops due to limited space in the laboratory, is $158.33 \mathrm{~m}$. The pipeline is partly curved with $180^{\circ}$ semi circles, a radius of curvature of $0.75 \mathrm{~m}$ and is fixed to a metal truss using 149 brackets (see Appendix A for their locations) to keep it in place and restrain the pipe from axial movement.

A schematic of the test rig setup with details of anchors is shown in Fig. 3. The properties of the pipeline are given in Table 1. The inner diameter and wall thickness have been measured, and Young's modulus and Poisson's ratio were provided by the pipe manufacturer. The axial stress and pressure wave speeds are determined theoretically using Eqs. (1) and (2), respectively. The retardation times and creep coefficients of the Kelvin-Voigt elements are calibrated using a hydraulic transient solver which incorporates the dynamic effect of pipe wall viscoelasticity (Covas et al., 2005; Keramat and Haghighi, 2014).

The upstream boundary condition is a constant pressure head determined by a transducer installed on top of the pressure vessel plus the difference in elevation between the inlet valve and the transducer. The constant pressure in the reservoir is maintained using an air compressor connected.

There are two valves at the downstream end (Fig. 3b): one is to control the steady flow (globe valve) and the other is to generate the transient event (ball valve) by suddenly closing it (within approximately $T_{c}=0.05 \mathrm{~s}$ ). The water discharges openly to atmosphere and is collected in a reservoir for reuse. The pressure data are collected at two locations: $0.3 \mathrm{~m}$ upstream of the ball valve (indicated by T1) and in the pressurized tank (T2). The piezoelectric pressure transmitters are of type WIKA S-11 with a measurement range of 0 to 16 bar and an accuracy of $0.1 \%$. The steady-state flow rate was measured by the volumetric method. The sampling frequency was $2000 \mathrm{~Hz}$. Fig. 3c shows a detailed picture of an anchor that may function as loose or as tight. The restrained anchor is fastened by two nuts at either sides of the screw hook and the loose anchor has the two nuts entirely open so that the pipe can move axially.

\section{Experimental results and discussion}

The experiments are designed to investigate FSI mechanisms and specifically Poisson coupling since its effect is inevitable in real pipe systems. The investigation is carried out by changing the support configurations by opening some brackets to enhance pipe motion. According to Tijsseling and Vardy (1996), two criteria need to be satisfied for FSI to be significant: the structural frequencies must (i) be higher than the resonance frequencies of the fluid column and (ii) be lower than the frequency content of the excitation, which is determined by pressure rise time, i.e. effective closure time, hammer hit duration, etc. As will be discussed later, in the experimental investigations the second criterion is not met, hence FSI effects are not entirely predominant. However, when transient signals are utilized for parameter estimation, FSI though small, can produce significant traces on the pressure signal, which support the notion of the need for FSI simulations.

\subsection{Configuration of supports}

The significance of FSI is investigated by assessing its dependence on the pipeline's support system. To this end, the effects of six different configurations of brackets, depicted in Fig. 4, on the waterhammer pressure heads are investigated. They include: all 149 brackets are restrained (Config. 1); only the two first brackets ahead of the valve, brackets numbered 
(a)
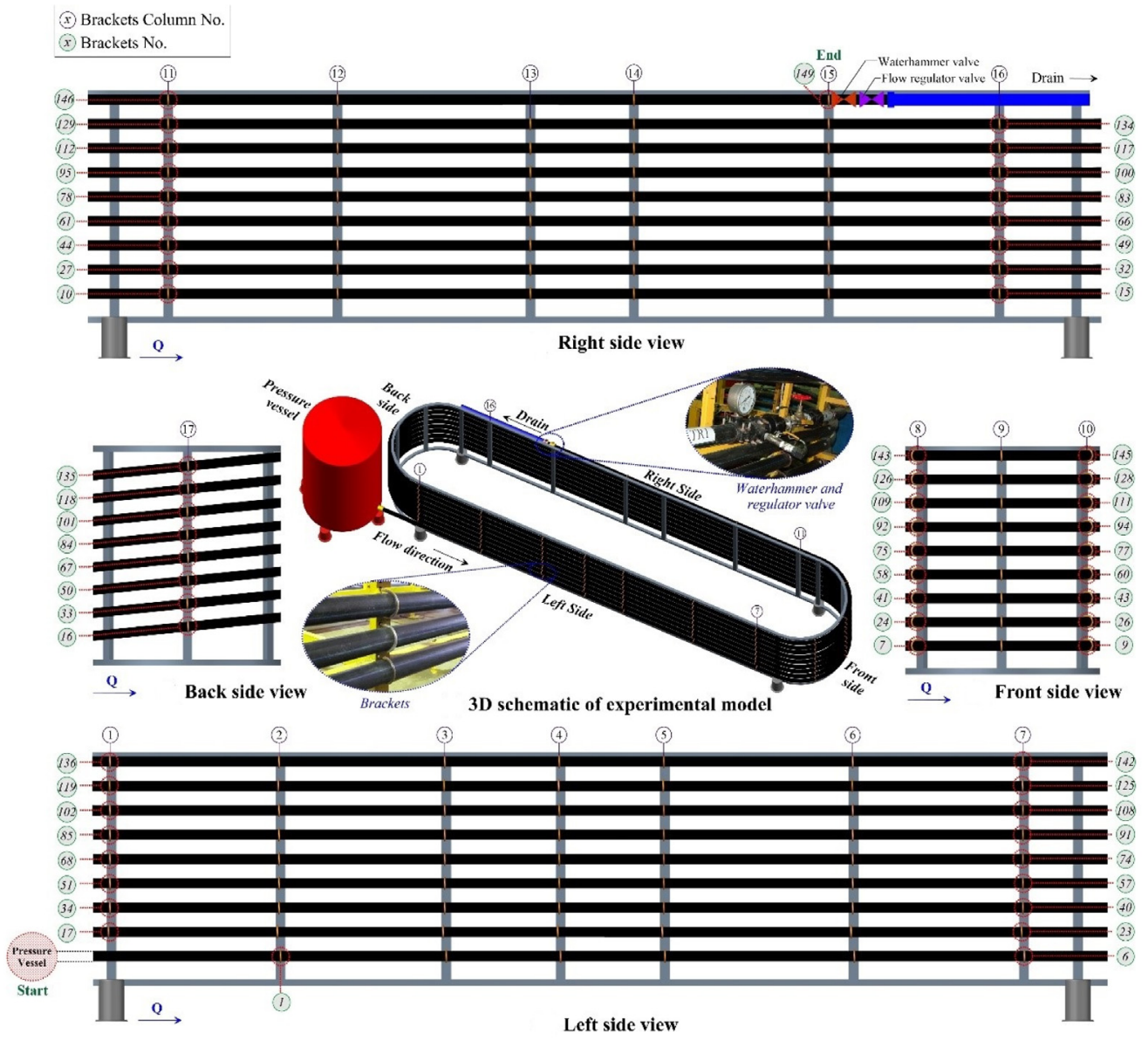

(b)

(c)
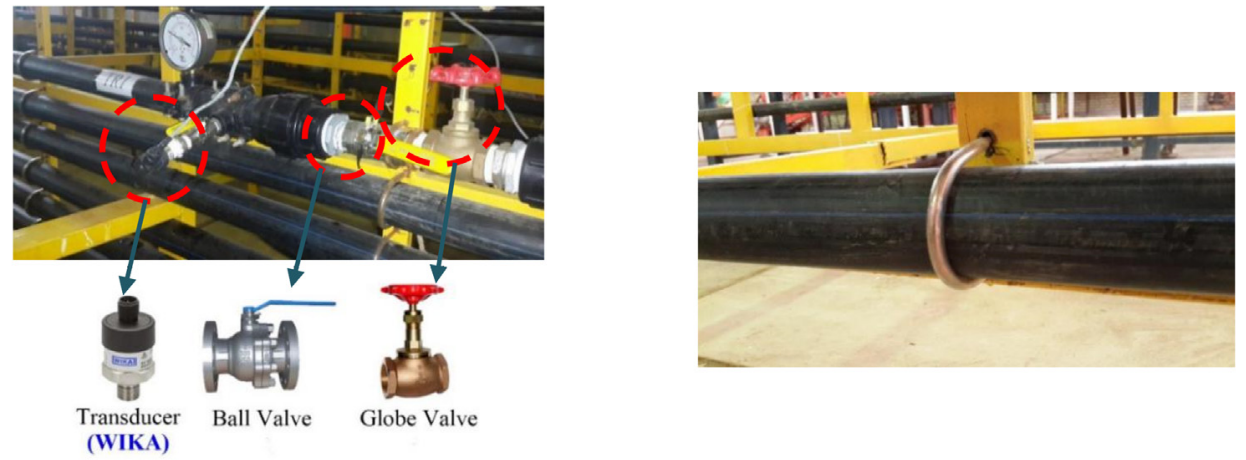

Fig. 3. Schematic view of experimental facility: (a) viscoelastic pipe system with anchors at bends and straight sections; (b) downstream valve and transducer, and (c) anchored bracket (tight).

147-148, are released (Config. 2); only brackets 139-141, 143-145 and 147-148 are released (Config. 3); brackets 139-141 and 143-148 are released (Config. 4); brackets 139-148 are released (Config. 5); brackets 138-141 are released (Config. 6). Note that the depicted arrangement of supports is the ideal situation which in reality is hard to achieve. As a result, a "restrained" anchor may fail to be tight enough during the dynamic loading or conversely, a "loosened" anchor may exhibit symptoms of a fixed support which can be manifested by preventing the propagation of the stress waves through the support. 


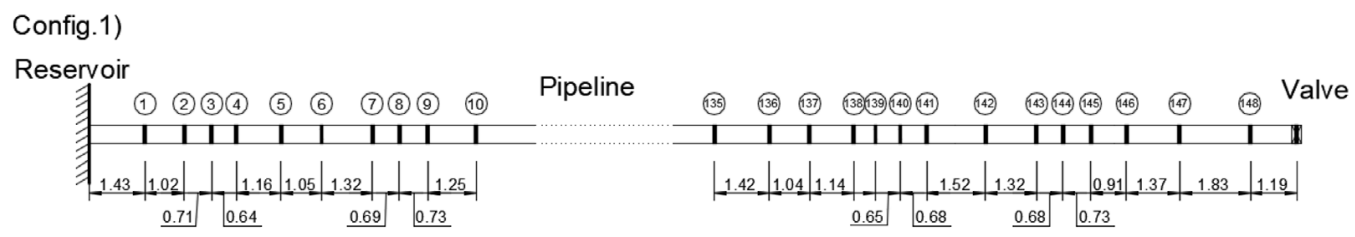

Config.2)
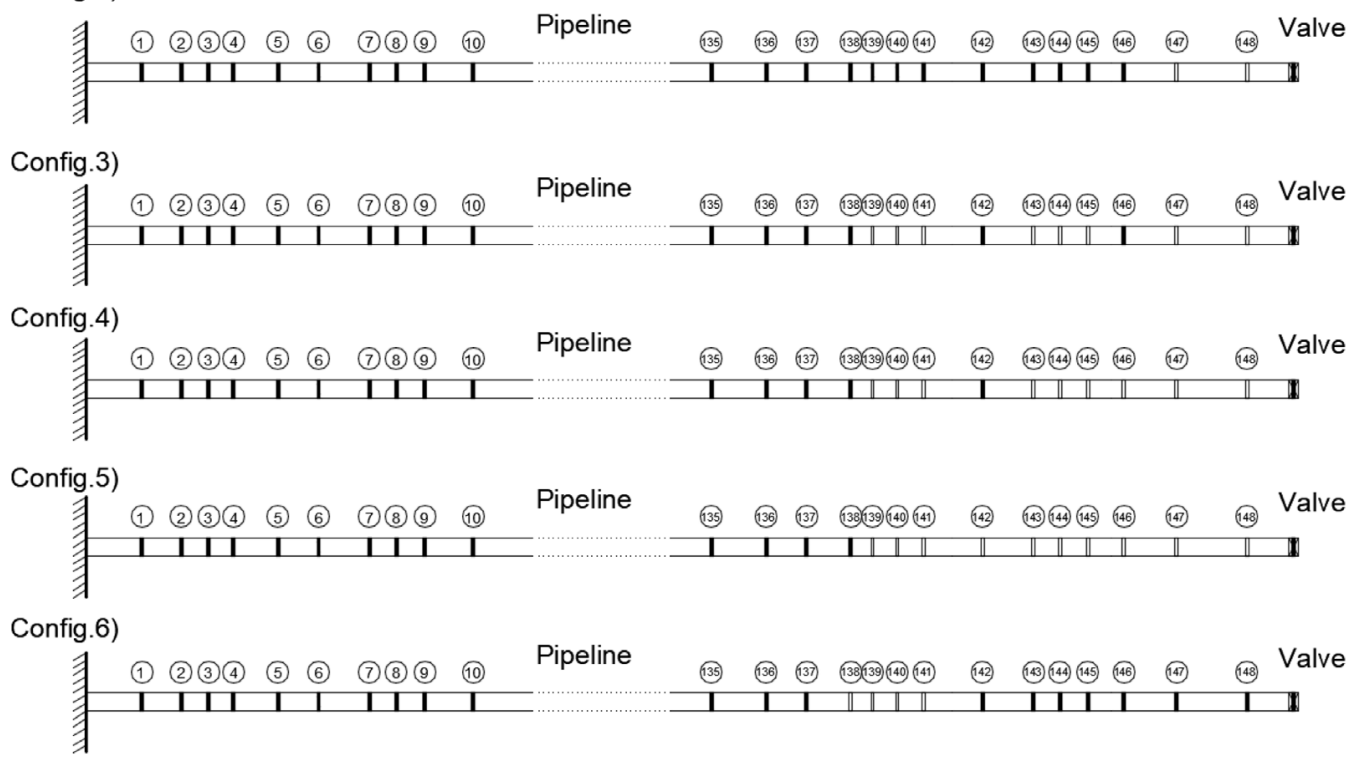

Fig. 4. Positions and idealized layout of the anchored (black) and released (white) brackets along the pipeline.

\subsection{Time domain measured signals}

The raw measured data are filtered (low pass) by a built-in smoothing function of MATLAB called "smooth". Fig. 5a shows raw data and a typical filtered data for Config. 1.

For each configuration, the same test is rerun two or three times to check the repeatability of the experiments (see Fig. $5 \mathrm{~b}$ for Config. 1). The experiments are also repeated for different initial flow rates as are depicted in Fig. $5 \mathrm{c}$, d for Config. 1. The shape of the pressure fluctuations on top of Joukowsky pressure head in Fig. $5 \mathrm{~b}-\mathrm{d}$ are quite similar in different experiments run at the same hydraulic conditions (Fig. 5b) or run for different flow rates (Fig. 5c, d). In Fig. 5d, $T^{*}=t /\left(4 L c_{f}^{-1}\right)$ and $H^{*}=\left(H-H_{0}\right) / H_{J k}$ in which $H_{J k}=V_{0} c_{f} / g$, and $H_{0}$ and $V_{0}$ are the initial pressure head and the flow velocity, respectively.

The pressure fluctuations displayed in Fig. 5 are not random (e.g. due to background noise) and indeed some physical mechanisms affect the results; evidently these are attributed to the supports as will be argued in the following. According to Fig. 5a, the physical fluctuations only appear clearly in the first half period, which reassures that they cannot be due to background noise and reveals that viscoelasticity has a higher damping rate for higher frequencies. Another interpretation is that the damping effects of the viscoelastic behavior of the pipe wall become dominant compared to the anchors effects in later periods.

The first half-period of pressure head at the valve is shown for Config. 1, 2 and 6 in Fig. 6a and for Config. 3, 4 and 5 in Fig. 6 b (note the dimensionless quantities $H^{*}, T^{*}$ already defined for Fig. 5d). By varying the location of anchored brackets, the reflection points for the axial stress waves in the pipe wall vary. This leads to different Poisson coupling contributions to the fluid pressures which are manifested by different shapes of pipe-vibration induced pressure fluctuations. A comparison between the excitation time, estimated approximately as $T_{c}=50 \mathrm{~ms}$ and the stress wave travel and return time between the valve and the first support ahead (number 138 with $z_{\text {valve }}-z_{138}=11.4 \mathrm{~m}$ in Config. 5), which is about $20 \mathrm{~ms}\left(c_{t}=1095 \mathrm{~m} / \mathrm{s}\right)$ reveals that the valve maneuver and the reflected stress waves act simultaneously on the pressure which makes it difficult to interpret the results in detail. However, the influence of supports on Poisson coupling is evident from the first half period after $t=T_{c}$.

\subsection{Comparison with numerical simulations}

A waterhammer solver which takes into account the viscoelastic effects of the pipe wall and FSI mechanisms in a multi-span pipeline (a pipeline with multiple-axial supports) developed by Zanganeh et al. $(2015,2019)$ is exploited to 
a)

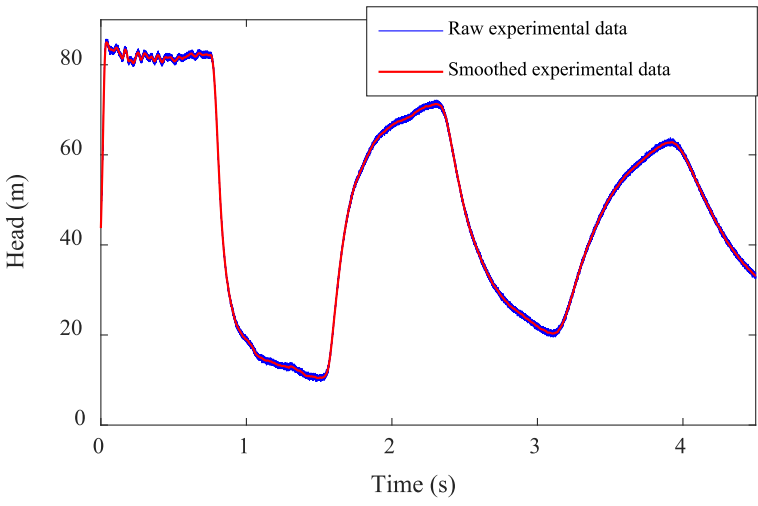

c)

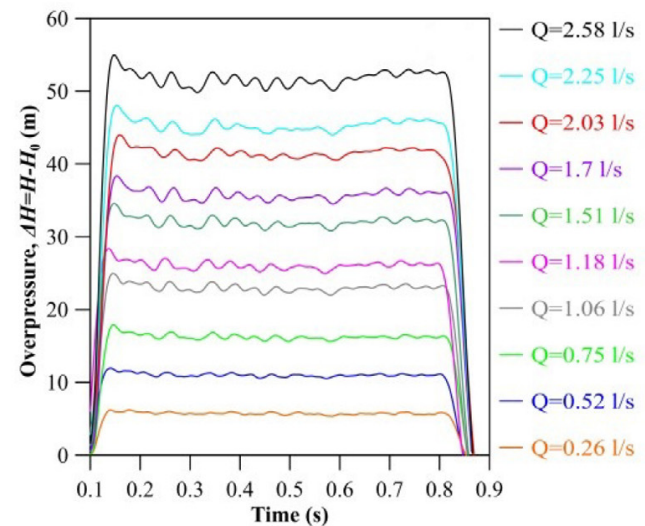

b)

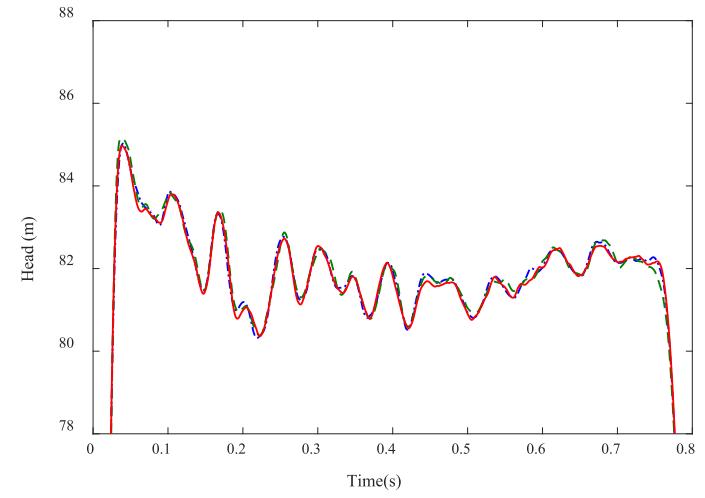

d)

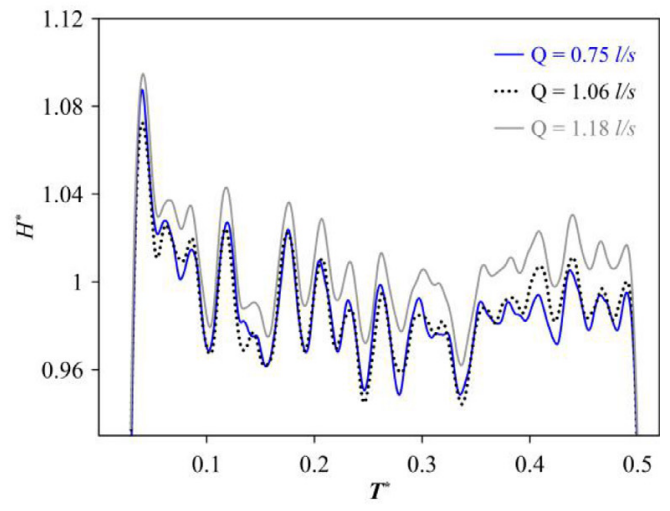

Fig. 5. Pressure heads of waterhammer tests in the pipe rig fixed with all 149 anchored brackets (Config. 1): (a) raw and smoothed experimental data of third run; (b) smoothed data of first, second and third run; (c) experimental smoothed data corresponding to different flow rates; and (d) dimensionless representation of pressure fluctuations for the indicated three flow rates, $H^{*}=\left(H-H_{0}\right) / H_{J k}, T^{*}=t /\left(4 L / c_{f}\right)$.
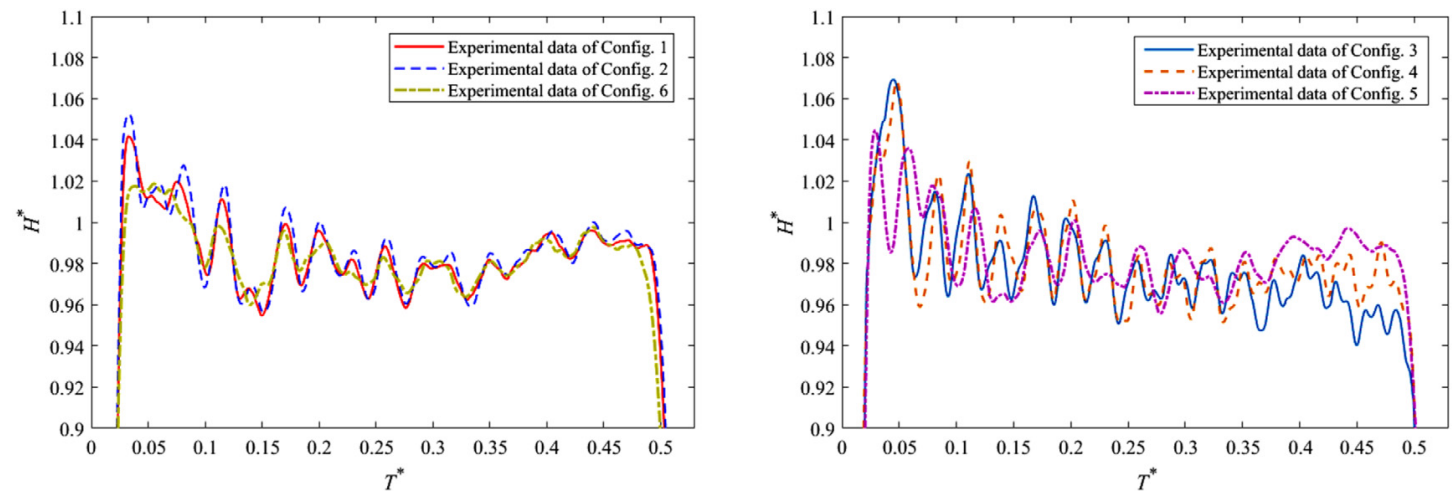

Fig. 6. Dimensionless pressure heads versus dimensionless time in the first half period of waterhammer for the six different configurations of anchors along the pipe, $H^{*}=\left(H-H_{0}\right) / H_{J k}, T^{*}=t /\left(4 L / c_{f}\right)$.

assess the collected pressure signals (see Appendix B for more information). The focus is placed on the anchors' effects on pressure responses which is most evident in the first half-period. For conciseness, among the six different supports arrangements (Fig. 4), configurations number 3 and 5 are examined with the numerical solver. Fig. 7 presents three signals obtained for Config. 3: (i) experimental data in continuous red line, (ii) numerical results with FSI in dashed-blue, and 

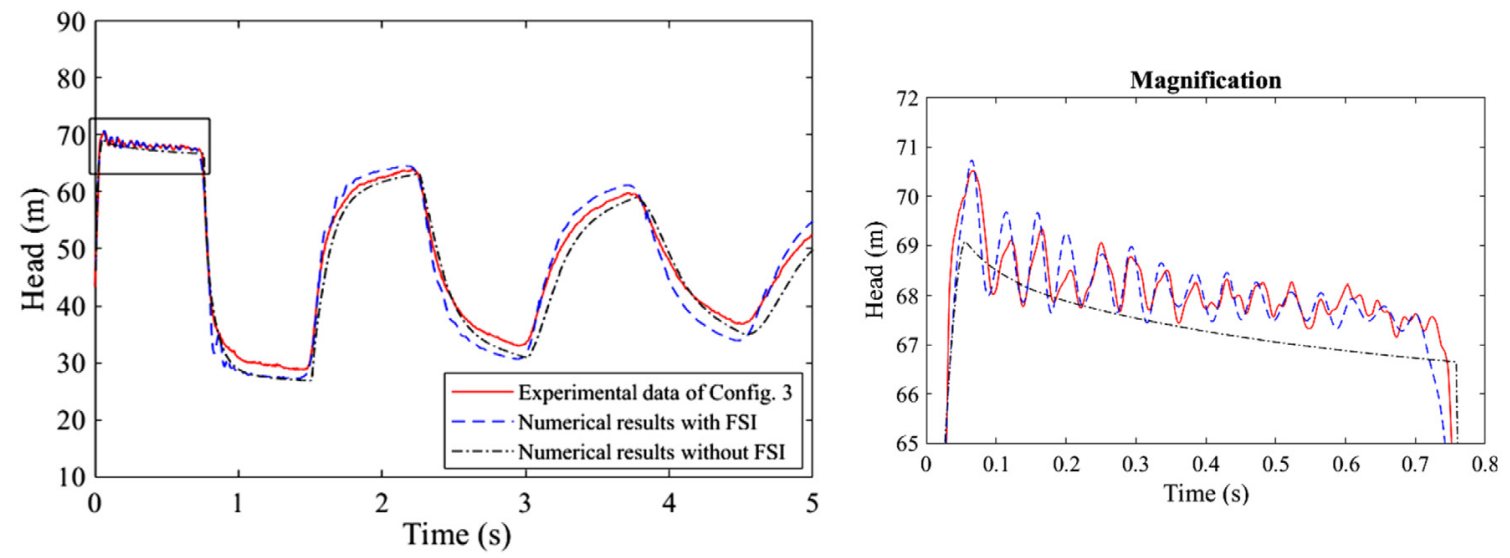

Fig. 7. Comparison between experimental and numerical results of pressure heads with and without FSI for Config. 3; the first half-period is magnified to the right.
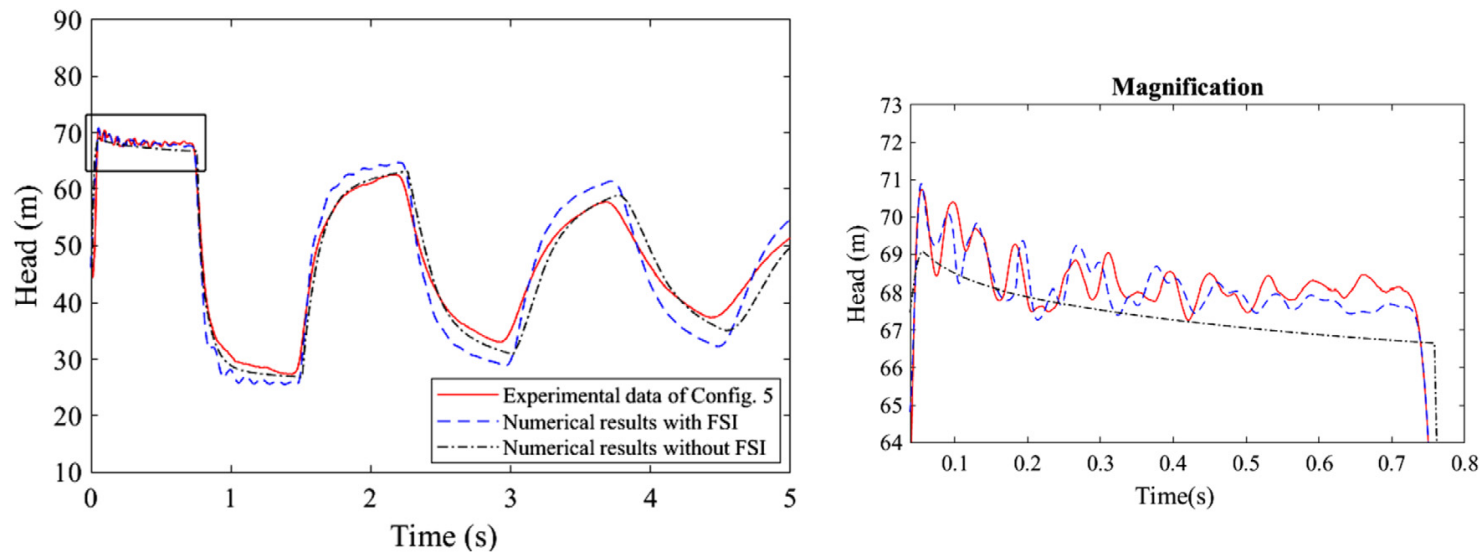

Fig. 8. Comparison between experimental and numerical results of pressure heads with and without FSI for Config. 5; the first half-period is magnified to the right.

(iii) numerical results without FSI in dash-dot black traces. Fig. 8 depicts similar comparison but for supports' Config. 5 . The computations with FSI show a better match with the experimental data. The discrepancy can be explained by the uncertainties in several system parameters including: stiffness of and friction at supports, mass of devices connected to the pipe, creep coefficients of pipe material, pipe flexure (bending), etc. Limitations of the adopted model (Zanganeh et al., $2015,2019)$ also contribute to the existing mismatch between computations and measurements, like incomplete models for unsteady friction and/or viscoelasticity, and pipe bends.

The comparisons demonstrate the non-negligible role of supports in pressure responses. This is especially of importance when transients are adopted for defect detection purposes. In these detection methods, timing and magnitude of pressure rises and drops (much similar to those of Figs. 7 and 8 in the first half-period), are crucial. The literature of waterhammerinduced FSI contains notable experimental and theoretical works about supports (Heinsbroek and Tijsseling, 1994; Wiggert and Tijsseling, 2001; Yang et al., 2004; Liu and Li, 2011; Henclik, 2012, 2018; Xu et al., 2014; Zanganeh et al., 2015, 2019; Ferras et al., 2017; Adamkowski et al., 2017). However, they lack studying the definite influence of supports on timing and magnitude of pressure jumps (or natural frequencies and amplitudes of pressure spectra), which allows to discriminate FSI-oriented pressure variations from anomaly-induced ones. Although the present laboratory experiments do not provide a solid support for quantification of these aspects, they virtually indicate the importance of FSI when a detailed shape of the transient response (in either time or frequency domain) is of interest.

\subsection{Frequency responses}

The target of this section is to study the influence of support positions in a short zone of about $12.5 \mathrm{~m}$ of pipe on the frequency spectrum of pressures he at downstream valve. The pressure amplitudes corresponding to frequencies are obtained using the fast Fourier transform (FFT) algorithm (Oppenheim et al., 1983; Lee et al., 2013) illustrated by Eq. (5) and implemented using the "fft" function in MATLAB. 

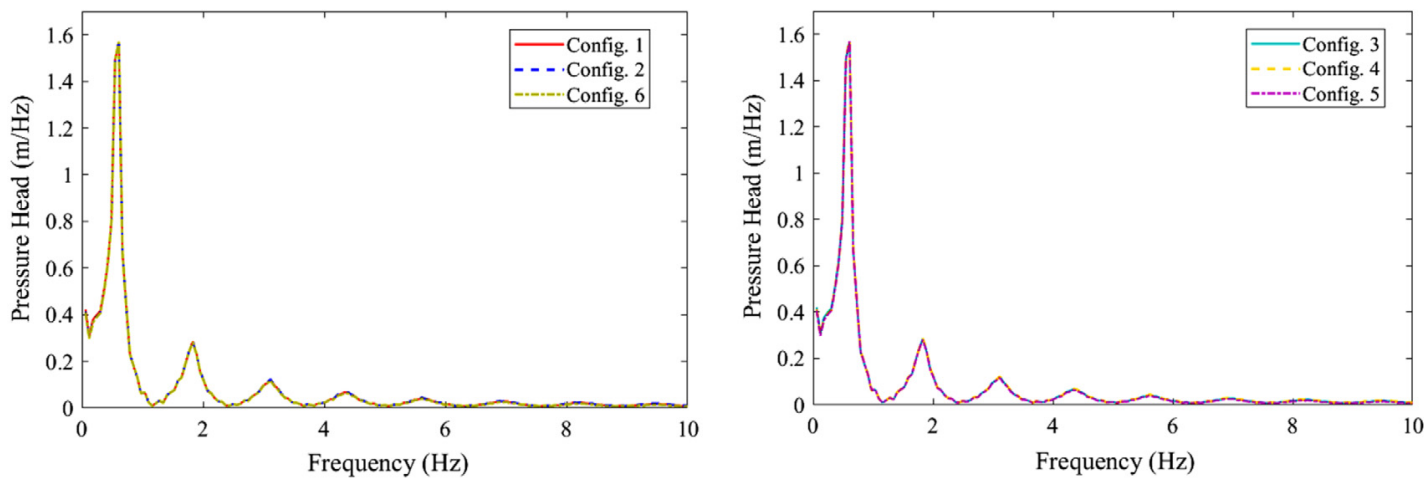

Fig. 9. Fourier amplitudes extracted from measured pressure heads (three and a half periods) for six different configurations of anchored brackets.

Table 2

Comparison between experimental (extracted from Fig. 9) and theoretical (determined by Eq. (3)) resonance frequencies in $\mathrm{Hz}$.

\begin{tabular}{lllllllll}
\hline Number of resonant frequency & 1 & 2 & 3 & 4 & 5 & 6 & 7 & 8 \\
\hline$f_{f}$, experiment, Fig. 9 & 0.6 & 1.9 & 3.3 & 4.4 & 5.8 & 7.0 & 8.3 & 9.6 \\
$f_{f}$ theoretical, Eq. (3) & 0.7 & 2.0 & 3.3 & 4.6 & 5.9 & 7.2 & 8.5 & 9.9 \\
\hline
\end{tabular}

\subsubsection{FFT of three and a half period}

Fig. 9 shows the pressure amplitudes for the six different configurations (Fig. 4) when measured pressure heads up to three and a half periods of waterhammer are employed to find the frequency content of the time signals. The natural frequencies of the fluid column are evident in Fig. 9. They are estimated by Eq. (2) and are provided in Table 2 along with those found in the experiments (Fig. 9). The two sets of natural frequencies show good agreement with each other. The discrepancy is likely due to inaccurate estimation of the wave speed in Eq. (2) as it neglects the retarded behavior of the viscoelastic pipe wall. A proper estimation of the wave speed for viscoelastic pipes in the frequency domain adopts the creep function (its transform in the frequency domain) which leads to a frequency-dependent phase velocity (wave speed) (Gong et al., 2015; Tijsseling and Vardy, 2015).

Fig. 9 also indicates that the fluid's spectrum is almost identical for all six configurations. The reason can be the fact that according to Figs. 5a, 6 and 7, the alternative support positions 1 to 6 solely affect the pressure time history of the first half-period, and not for later times. Consequently, the FSI-induced pressure fluctuations in the first half-period contribute less to the FFT procedure when the time data of several periods (which are more or less similar for all configurations) are utilized. The damping of amplitudes observed in Fig. 9 is mainly due to viscoelasticity (Keramat et al., 2013, Lee et al., 2013, Wang et al., 2019a, 2019b, Gong et al., 2015) and unsteady friction (Duan et al., 2010; Meniconi et al., 2014).

In our FSI experiment, one should inspect one crucial finding of Zhang et al.'s (1999) research: the most significant deviations of natural frequencies of fluid pressure occur around structural natural frequencies. To this aim, among the six configurations, the lowest structural frequency which belongs to Config. 5 (Fig. 4) and which corresponds to the wave propagation between the downstream valve and support no. 138 is computed: $f_{s s}=\frac{1}{2} c_{t}\left(z_{\mathrm{valve}}-z_{138}\right)^{-1}=$ $0.5 \times 1095 / 11.4=48 \mathrm{~Hz}$. It is clear from Fig. 9 that this frequency will not have a significant effect on the pressure head spectrum so that the aforementioned statement about FSI cannot be investigated herein.

\subsubsection{FFT of the first half-period}

The main aim of the frequency-domain investigations is to perceive the traces of the anchors' influence on Poisson coupling and consequently on the frequency spectra of pressure heads. To this end, Fig. 10 shows the same results as Fig. 9 when only the top trace of the first half-period of transients (depicted in Fig. 6) is employed for FFT. Unlike Fig. 9, in Fig. 10 the impact of alternative anchored brackets configuration is visible. The reason for the jagged curves is the use of a short time span (first half-period), and hence insufficient time for the FFT scheme. These pressure spectra also do not show a rigorous record of the structural vibration.

To resolve the issue of the inappropriate time span for the generation of the spectrums, two amendments are adopted on the time signals. The first half-period of waterhammer in each signal is repeated 30 times (more repetitions show no significant change in the spectra) to construct an appropriate data time series for estimating Fourier amplitudes. In addition, the signal is shifted by one time step $\Delta t$ and then it is subtracted from the original signal so as to make an impulse signal in time: $H_{\text {impulse }}=H(t+\Delta t)-H(t)$. Having done this, the input signal to the FFT operator is of finiteenergy form, which is valid for the Fourier transform (Lee et al., 2013). Note that no significant difference appears if the two procedures are applied in reverse order. The resulting signal from the two procedures is shown in Fig. 11 (for Config. 5 ), but it displays only 4 repetitions for a clear presentation. 

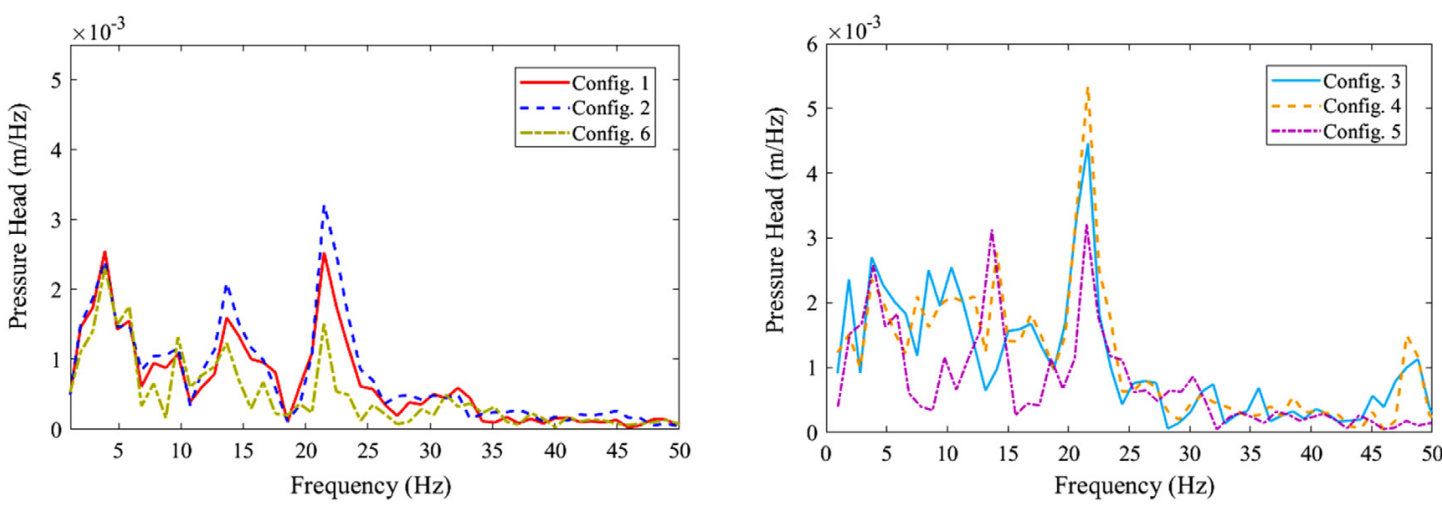

Fig. 10. Fourier amplitudes extracted from first half-period of pressure heads for six different configurations of anchored brackets.

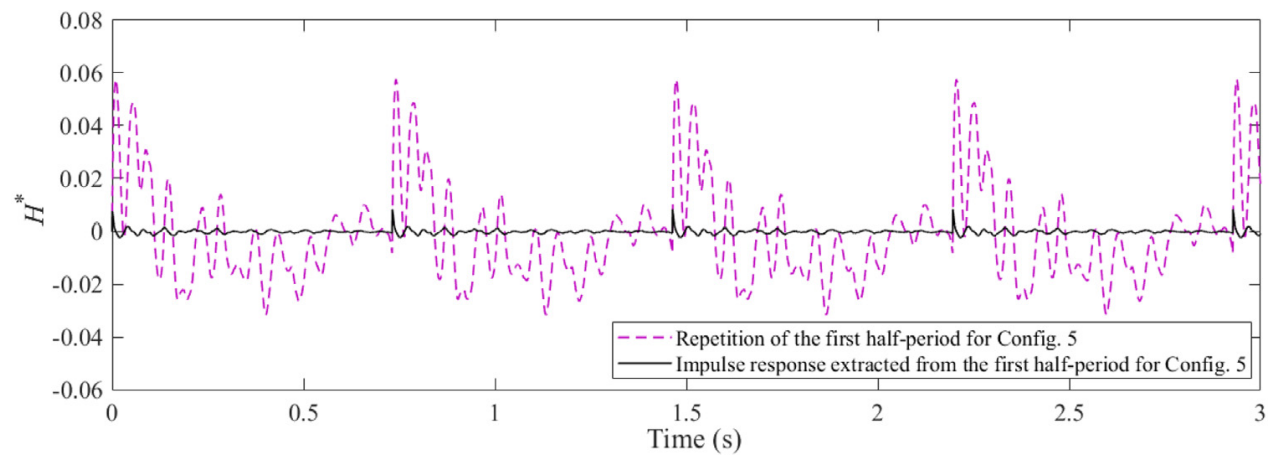

Fig. 11. The impulse response in time generated from the time signal of measured pressure for Config. 5.

Table 3

Comparison between the observed (extracted from Fig. 11) and theoretical frequencies determined by Eq. (3).

\begin{tabular}{lllllllllllllll}
\hline Observed & 1.4 & 2.7 & 4.1 & 5.4 & 6.8 & 8.2 & 9.5 & 10.9 & 12.3 & 13.6 & 15 & 16.4 & 17.8 & 19.1 \\
\hline$f_{f}=n c_{f}(2 L)^{-1}$ & 1.4 & 2.7 & 4.1 & 5.4 & 6.8 & 8.2 & 9.5 & 10.9 & 12.2 & 13.6 & 15 & 16.3 & 17.7 & 19.1 \\
\hline
\end{tabular}

The frequency spectra corresponding to the time series (pulse signals) are provided in Fig. 12 which are in fact refined versions of Fig. 10. Since the top trace of the first half period with the duration $T_{d}=0.731 \mathrm{~s}$ is repeated to construct the spectrum of pressures, the fluid resonance frequencies are in fact equivalent to those of an "artificial" system with frequencies dictated by $n / T_{d}=n f_{d}=1.368 \times n \mathrm{~Hz}, n=1,2, \ldots$, which is equivalent to frequencies of a symmetric system evaluated by $n c_{f} /(2 L), n=1,2, \ldots$ with $L=158.33$ and $c_{f_{e}}=431 \mathrm{~m} / \mathrm{s}$ (estimated in accordance with $T_{d}$ ). Therefore, they are totally different from those of Table 2. Called artificial natural frequencies herein, Table 3 shows the agreement between the frequencies determined by $n c_{f} /(2 L)$ and those extracted from Fig. 12 . The base frequency $f_{d}=1.368 \mathrm{~Hz}$ may be viewed as the resolution of the spectrum: a smaller number for $T_{d}$ (a shorter time span for duplication) leads to a larger $f_{d}$ and hence less resolution (lower accuracy) for the spectra presented in Fig. 12.

The amplitudes corresponding to the discrete frequencies (obtained by integer orders of $f_{d}$ ) illustrate the role of FSI in the frequency spectra, because in the absence of FSI, all the artificial natural frequencies have the same amplitude. As observed in Fig. 12, the signature of the structural frequencies seems to establish a pattern on the amplitudes of each artificial natural frequency. There is not a large discrepancy between various amplitudes in the pressure spectrum because the various pipe configurations differ only in the supports of a short region of around $12.5 \mathrm{~m}$. However, one can clearly conclude that Config. 1, 2 and 6 belong to the situation of less FSI effect than Config. 4 and 5 in which a few more natural frequencies of the pipe structure are observed. In fact, taking away some supports (e.g. in Configs. 4 and 5) enhances the Poisson coupling, thus producing new frequencies, which cause the indicated larger amplitudes in the pressure spectrum (corresponding to frequencies $12.3 \mathrm{~Hz}$ and $10.9 \mathrm{~Hz}$ in Configs. 4 and 5). One can predict that these frequencies should be less than $22 \mathrm{~Hz}$ (the main frequency which is common in all configurations) because Configs. 4 and 5 are more flexible, knowing that the more flexible system, the lower fundamental frequency.

The fact that all six configurations tend to vibrate with the dominant frequency of about $22 \mathrm{~Hz}$, can be studied by the time domain signals in Fig. 6. The fluctuations of the Configs. 1, 2, and 6 are analogous but they are of different pattern 

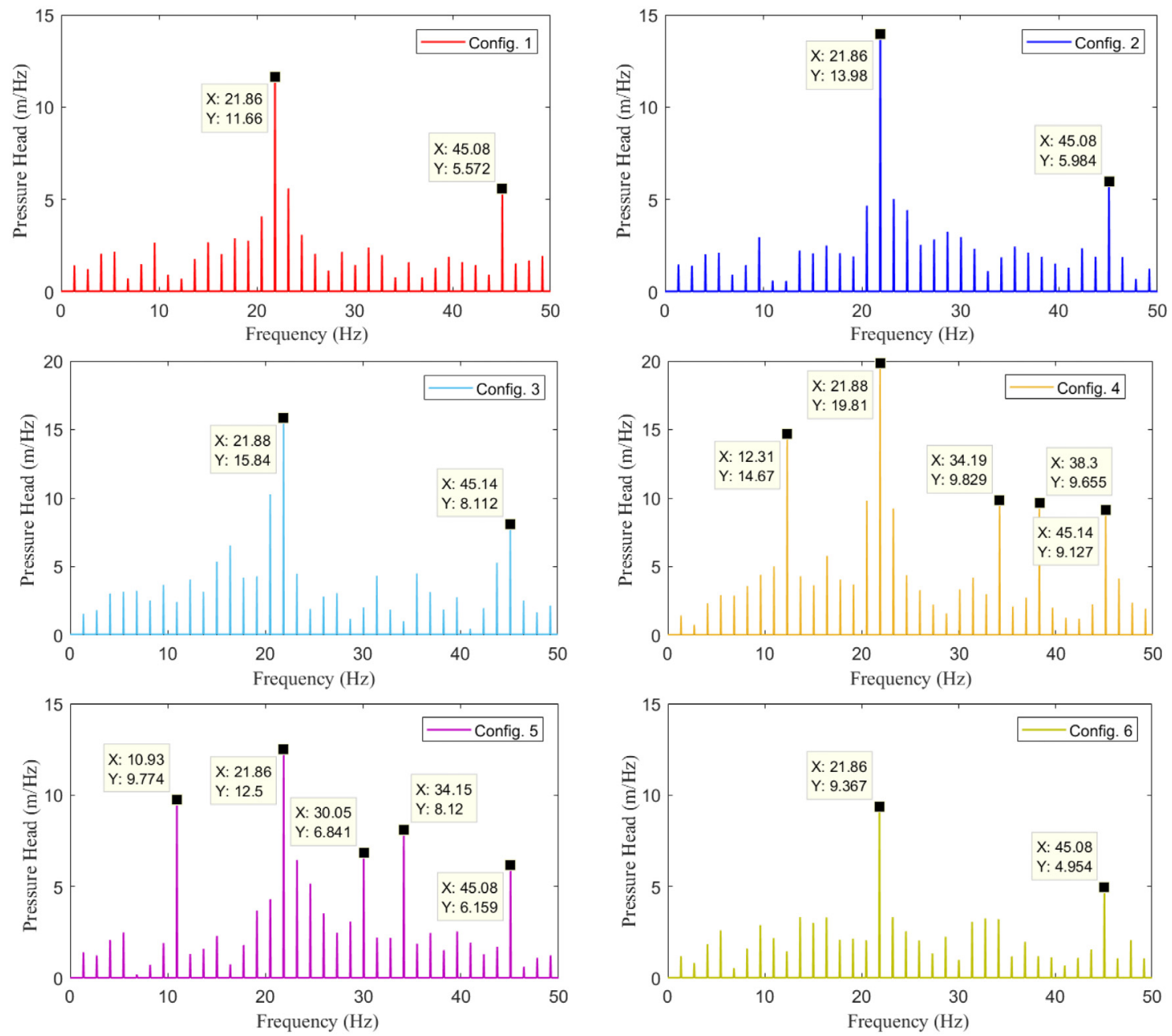

Fig. 12. Fourier amplitudes corresponding to impulse signals generated from the pressure measurements for the six supports configurations.

compared to those of Configs. 3, 4 and 5. In the latter configurations, the oscillations in the time domain signals have different patterns like the corresponding spectrums that show different natural frequencies.

A comparison between the natural frequencies of Configs. 1 and 2 reveals that by releasing the two anchors upstream the excitation valve does not considerably affect the pipe structural flexibility. The reason was that the free span between supports was too short to manifest new frequencies due to the Poisson coupling or that the supposedly open anchors had still a slight connection to the pipe rack.

The dominant frequency of about $22 \mathrm{~Hz}$ may be explained by two hypotheses as follows. (1) The whole pipe rack to which the pipeline is connected (by means of the anchors) vibrates with this frequency hence an external agent dictates this motion. Hence, there might be a relation between the pressure rise time (closure time of valve) $T_{c}=50 \mathrm{~ms}$ and the frequency of the forced vibrations given by $f=T_{c}^{-1}=20 \mathrm{~Hz}$. (2) The pipe system can be simulated as a SDOF system as explained via Eq. (4); this is elaborated in the next section.

Finally, the first resonance frequency according to Eq. (3) for a symmetric system is $f_{s s}=0.5 c_{t} /\left(z_{\text {valve }}-z_{138}\right)=$ $0.5 \times 1095 / 11.4=48 \mathrm{~Hz}$ and for anti-symmetric system (only possible if the valve had a loosen connection to the pipe rack) it yields $f_{s a}=0.25 c_{t} /\left(z_{\text {valve }}-z_{138}\right)=24 \mathrm{~Hz}$, which are rough approximations of those identified in the pressure spectrums.

\subsubsection{MDOF model of pipeline structure}

Before presenting the model, some issues regarding the theoretical analysis of FSI during waterhammer in a pipe system with multiple supports are highlighted. The structural resonant frequencies of such system may be found from a frequency-domain solution (e.g. using Laplace or Fourier transforms or the transfer function approach) of the so called extended partial differential equations of waterhammer (Wiggert and Tijsseling, 2001). Alternatively, the pipeline 
(a)

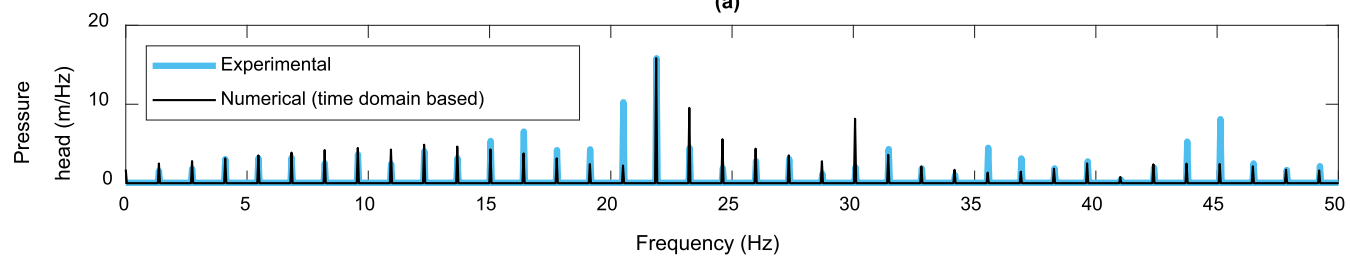

(b)

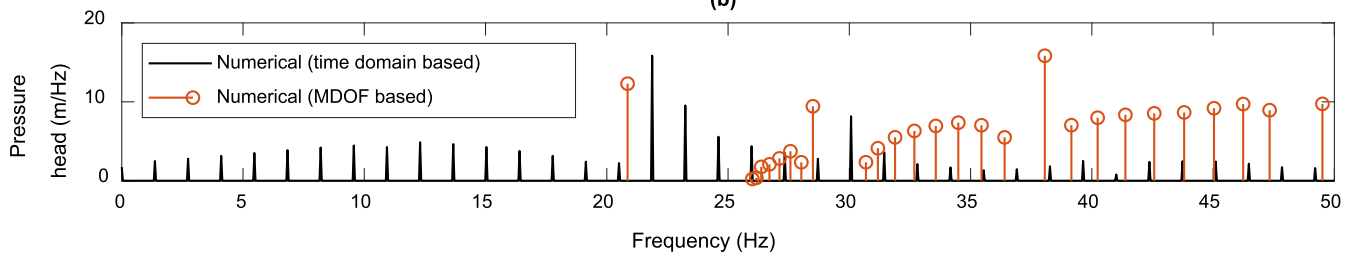

(c)

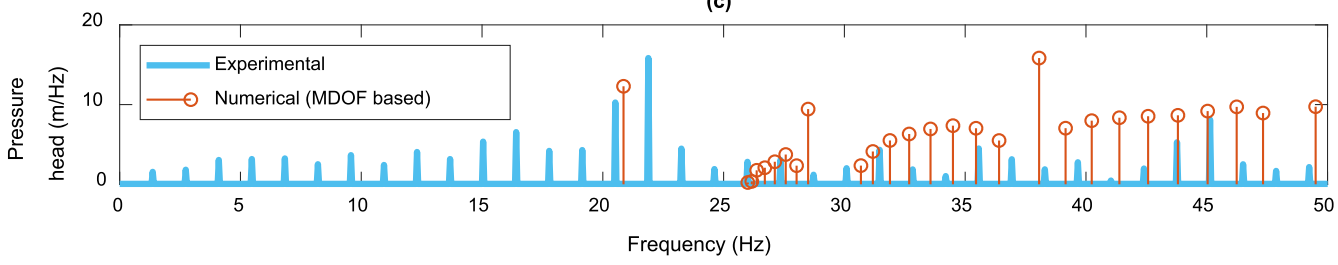

Fig. 13. Frequency spectra of experimental pressure signal (a), time-domain simulation (b) and MDOF model (c) for Config. 3.

with its multiple supports may be viewed as a MDOF system described by a system of ordinary differential equations. The eigenvalues and eigenmodes of such system allow for finding the frequency spectrum of the pipe vibration. The manifestation of structural frequencies is then visible in the pressure spectrum of the system. In any case, a detailed information of the stiffness of supports, which is an uncertain quantity in the current experiment and in practice, is necessary.

The pipeline structure of Config. 3 (Fig. 4) is synthesized as a MDOF system with the details explained in Appendix C, in which the boundary supports are fixed and the stiffness of all middle supports are set to $k^{s}=1.46 \times 10^{8} \mathrm{~N} \mathrm{~m}^{-1}$. The frequency spectrum of displacement for Config. 3 is presented in Fig. 13, along with the spectrum of pressure for the experimental data (Fig. 12-Config. 3) and the frequency response corresponding to the time domain computation. The latter is made by the FFT of the pulse signal corresponding to the numerical result presented in Fig. 7 (with FSI). The three results (experimental, numerical based on the MDOF model and numerical based on FFT of the time-domain simulation) are compared two by two in Fig. 13a-c.

Fig. 13a, which is in fact the frequency spectrum presentation of Fig. 7 (comparison between the experimental and numerical results for Config. 3) illustrates the frequency content of the structural vibrations in the two signals. The agreement is acceptable especially for the dominant frequency of about $22 \mathrm{~Hz}$ and the discrepancy is explained earlier (see the discussion of Fig. 7).

Fig. 13b compares the spectra of the time domain computation (considering FSI) with the results of the MDOF model of the pipeline. It illustrates the contribution of different eigen modes at the valve location predicted by the MDOF model for a free vibration. The reason of a considerable difference between the amplitudes at the second half of the graph (say at frequencies higher than $30 \mathrm{~Hz}$ ) is the assumptions of free vibration and negligible structural damping in the MDOF model. The dominant frequencies of the two spectra (21.9, 30.1 and $39.6 \mathrm{~Hz}$ for the time-domain based, and 20.9, 28.5 and $38.1 \mathrm{~Hz}$ for the MDOF model) are fairly matched considering that the application of the first half period dictates a resolution accuracy of $f_{d}= \pm 1.368 \mathrm{~Hz}$ as discussed. If use is made of a longer time span, a better match is achieved but due to the aforementioned restriction on the selected time duration for FFT, only the first half period of waterhammer is exploited to generate all the spectra in Fig. 13.

Fig. 13c compares the frequency spectrum obtained by the MDOF model with that of the experiment for the Config. 3. This figure reveals that the pipeline structure of Config. 3 tends to vibrate with the effective frequency of $20.9 \mathrm{~Hz}$ which demonstrates that the oscillations observed in the pressure signals at the first half period have been induced by structural vibrations.

\section{Summary and conclusions}

The trace of discrete (e.g. leaks) and extended defects (e.g. blockages) on transient fluid pressures in pipes has been widely investigated experimentally and numerically. However, research on the significance of pipe supports on transient 
responses are rare. This research aimed to address the traces of supports (their location and stiffness) on pressure signal both in time and frequency domains via controlled laboratory experiments. The tests were carried out on transients in a $158.33 \mathrm{~m}$ viscoelastic pipeline in which some anchors are released sequentially leading to six different arrangements of supports.

A support behaves as a discrete component to restrain the pipe movements. The anchor supports have small, but important, impacts on fluid variables (pressure, velocity) via FSI mechanisms. The research demonstrated that a model with FSI produces closer results to the experimental data with the investigations in time and frequency domain. Based on the conducted experiments, the key findings of this research are:

- The experiments revealed significant physical fluctuations on the pressure time histories whose pattern was primarily dictated by the arrangement of supports.

- To retain the impact of FSI-induced oscillations observed in the time signals while using FFT, only the first half-period should be incorporated. No manifestation of FSI was identified if data up to several periods of time were utilized to construct the frequency spectrum.

- When the first half-period was employed for the FFT, the frequency content of the signal merges with the dominant frequencies dictated by the time span used for the periodic signal construction. Then, the amplitudes corresponding to such resonant frequencies were primarily affected by the arrangement of supports.

- The specific pattern of the amplitudes stemming from the anchors (location and stiffness) proposes the notion of identification of supports' characteristics using inverse analysis. This is much similar to the widely established frequency-response based methods (using fluid pressure) for the detection of discrete defects.

- The numerical simulation based on an idealized configuration of supports predicted the FSI-induced pressure fluctuations reasonably well.

\section{Declaration of competing interest}

One or more of the authors of this paper have disclosed potential or pertinent conflicts of interest, which may include receipt of payment, either direct or indirect, institutional support, or association with an entity in the biomedical field which may be perceived to have potential conflict of interest with this work. For full disclosure statements refer to https: //doi.org/10.1016/j.jfluidstructs.2019.102848.

\section{CRediT authorship contribution statement}

Alireza Keramat: Supervision, Project administration, Conceptualization, Methodology, Software, Investigation, Validation, Writing - original draft, Writing - review \& editing. Manoochehr Fathi-Moghadam: Funding acquisition, Data curation, Writing - review \& editing. Roohollah Zanganeh: Writing - original draft, Methodology, Software, Validation, Visualization. Mostafa Rahmanshahi: Data curation, Formal analysis, Visualization, Writing - original draft. Arris S. Tijsseling: Investigation, Conceptualization, Writing - review \& editing. Ebrahim Jabbari: Investigation, Writing - review \& editing.

\section{Acknowledgments}

All the institutions that the authors are affiliated with are acknowledged.

\section{Appendix A. Location of anchors}

The location of anchors along the pipeline for the experiment are specified in Table A.1.

\section{Appendix B. Numerical simulation approach}

\section{Governing equations}

The governing equations, describing extended waterhammer in viscoelastic pipes (Keramat et al., 2012), are fluid momentum:

$$
\frac{\partial Q}{\partial t}+g A_{f} \frac{\partial \tilde{H}}{\partial z}=0
$$

fluid continuity:

$$
\frac{1}{A_{f}} \frac{\partial Q}{\partial z}+\frac{g}{c_{f}^{2}} \frac{\partial \tilde{H}}{\partial t}-2 v \frac{\partial \dot{u}_{z}}{\partial z}=\left(v^{2}-1\right) \rho_{f} g \frac{D}{e} \frac{\partial I_{\tilde{H}}}{\partial t},
$$


Table A.1

Anchors' location.

\begin{tabular}{|c|c|c|c|c|c|c|c|c|c|}
\hline Anchor number & $z(\mathrm{~cm})$ & Anchor number & $z(\mathrm{~cm})$ & Anchor number & $z(\mathrm{~cm})$ & Anchor number & $z(\mathrm{~cm})$ & Anchor number & $z(\mathrm{~cm})$ \\
\hline Reservoir & 0 & 30 & 3094.2 & 60 & 6290.6 & 90 & 9521.5 & 120 & 12775.5 \\
\hline 1 & 143 & 31 & 3214.7 & 61 & 6414.6 & 91 & 9625.5 & 121 & 12875.5 \\
\hline 2 & 245 & 32 & 3320.2 & 62 & 6519.4 & 92 & 9755.5 & 122 & 12944.5 \\
\hline 3 & 315.5 & 33 & 3514.2 & 63 & 6638.4 & 93 & 9824.5 & 123 & 13008.5 \\
\hline 4 & 379.5 & 34 & 3656.2 & 64 & 6702.4 & 94 & 9897.5 & 124 & 13124.5 \\
\hline 5 & 495.8 & 35 & 3760.2 & 65 & 6822.9 & 95 & 10021.5 & 125 & 13228.5 \\
\hline 6 & 600.5 & 36 & 3860.2 & 66 & 6928.4 & 96 & 10126 & 126 & 13358.5 \\
\hline 7 & 731 & 37 & 3929.7 & 67 & 7122.4 & 97 & 10245 & 127 & 13427.5 \\
\hline 8 & 800.3 & 38 & 3993.7 & 68 & 7264.4 & 98 & 10309 & 128 & 13500.5 \\
\hline 9 & 873.3 & 39 & 4109.7 & 69 & 7368.4 & 99 & 10429 & 129 & 13624.5 \\
\hline 10 & 997.8 & 40 & 4213.7 & 70 & 7468.4 & 100 & 10534 & 130 & 13729 \\
\hline 11 & 1102.6 & 41 & 4344.2 & 71 & 7537.9 & 101 & 10728 & 131 & 13848 \\
\hline 12 & 1221.6 & 42 & 4413.5 & 72 & 7601.9 & 102 & 10870 & 132 & 13912 \\
\hline 13 & 1285.6 & 43 & 4486.5 & 73 & 7717.9 & 103 & 10974 & 133 & 14032 \\
\hline 14 & 1406.1 & 44 & 4610.5 & 74 & 7821.9 & 104 & 11074 & 134 & 14137 \\
\hline 15 & 1511.6 & 45 & 4715.3 & 75 & 7952.4 & 105 & 11143 & 135 & 14331 \\
\hline 16 & 1705.6 & 46 & 4834.3 & 76 & 8021.7 & 106 & 11207 & 136 & 14473 \\
\hline 17 & 1847.6 & 47 & 4898.3 & 77 & 8094.7 & 107 & 11323 & 137 & 14577 \\
\hline 18 & 1951.6 & 48 & 5018.8 & 78 & 8218.7 & 108 & 11427 & 138 & 14691 \\
\hline 19 & 2053.6 & 49 & 5124.3 & 79 & 8323.5 & 109 & 11557 & 139 & 14746.5 \\
\hline 20 & 2124.1 & 50 & 5318.3 & 80 & 8442.5 & 110 & 11626 & 140 & 14811 \\
\hline 21 & 2188.1 & 51 & 5460.3 & 81 & 8506.5 & 111 & 11699 & 141 & 14879 \\
\hline 22 & 2304.4 & 52 & 5564.3 & 82 & 8627 & 112 & 11823 & 142 & 15030.5 \\
\hline 23 & 2409.1 & 53 & 5664.3 & 83 & 8732.5 & 113 & 11927.5 & 143 & 15162 \\
\hline 24 & 2539.6 & 54 & 5733.8 & 84 & 8926.5 & 114 & 12046.5 & 144 & 15230 \\
\hline 25 & 2608.9 & 55 & 5797.8 & 85 & 9068.5 & 115 & 12110.5 & 145 & 15303 \\
\hline 26 & 2681.9 & 56 & 5913.8 & 86 & 9172.5 & 116 & 12230.5 & 146 & 15394 \\
\hline 27 & 2806.4 & 57 & 6017.8 & 87 & 9272.5 & 117 & 12335.5 & 147 & 15530.5 \\
\hline 28 & 2911.2 & 58 & 6148.3 & 88 & 9341.5 & 118 & 12529.5 & 148 & 15713 \\
\hline 29 & 3030.2 & 59 & 6217.6 & 89 & 9405.5 & 119 & 12671.5 & 149 (valve) & 15833 \\
\hline
\end{tabular}

and longitudinal vibration of the pipe-wall:

$$
\frac{\partial^{2} u_{z}}{\partial t^{2}}-c_{t}^{2} \frac{\partial^{2} u_{z}}{\partial z^{2}}-g \frac{\rho_{f}}{\rho_{t}} \frac{v D}{2 e} \frac{\partial \tilde{H}}{\partial z}=E_{0} g \frac{\rho_{f}}{\rho_{t}} \frac{v D}{2 e} \frac{\partial I_{\tilde{H}}}{\partial z}-E_{0} I_{i_{z}} .
$$

In these equations $Q=A_{f} V$ is the flow rate, $A_{f}$ is the cross-sectional area of flow, $V$ is the average fluid velocity, $z$ is the pipe axis coordinate, $t$ is time, $\tilde{H}(t, z)=H(t, z)-H_{0}(z)$ is the fluid dynamic pressure head (with $H_{0}$ being constant in a frictionless and horizontal pipeline), $v$ is Poisson's ratio, $D$ is the inner pipe diameter, $e$ is the wall thickness, $g$ is the gravitational acceleration, $\rho_{f}$ is the fluid density, $\rho_{t}$ is the density of the pipe wall material, $E_{0}$ is Young's modulus of elasticity corresponding to the immediate hoop strain $\left(E_{0}=E\right.$ in an elastic pipe), $\dot{u}_{z}$ is the axial pipe velocity, $u_{z}$ is the axial pipe displacement, $c_{t}{ }^{2}=E_{0} / \rho_{t}$ is the uncoupled axial wave speed in the pipe wall, and $c_{f}$ is the uncoupled pressure wave speed defined by Eq. (2),

$$
c_{f}:=\left(\rho_{f}\left(\frac{1}{K}+\left(1-v^{2}\right) \frac{D}{e E_{0}}\right)\right)^{-\frac{1}{2}},
$$

where $K$ is the bulk modulus of the liquid.

The viscoelastic variable $I_{\tilde{H}}$ is proportional to the retarded circumferential strain and $I_{i_{z}}$ is proportional to the retarded axial stress gradient caused by inertia forces; they are obtained from the following relation:

$$
I_{h}:=\int_{0}^{t} h(t-s) \frac{\mathrm{d} J(s)}{\mathrm{d} s} \mathrm{~d} s=\sum_{k=1}^{N_{K V}}\left(\frac{J_{k}}{\tau_{k}} \int_{0}^{t} h(t-s) \mathrm{e}^{-\frac{s}{\tau_{k}}} \mathrm{~d} s\right),
$$

in which $h(t)$ is representative of $\tilde{H}, \ddot{u}_{z}$ functions, $N_{K V}, J(t)$ and $\tau(t)$ are the number of elements, creep compliance function, and retardation time in the generalized Kelvin-Voigt model, respectively. If the right-hand sides of Eqs. (B.2) and (B.3) are ignored, the governing equations are those for elastic pipes (Lavooij and Tijsseling, 1991; Tijsseling, 1996). If in addition $v=0$, the conventional waterhammer equations without FSI remain.

\section{Initial and boundary conditions}

- Initial conditions

The system considered is a reservoir-pipe-valve system where the initial condition for the fluid is a constant discharge $Q_{0}$ and a constant head $H_{0}$, and for the pipe wall it is of zero velocity, displacement, stress and strain.

- Boundary conditions 
The upstream reservoir has a constant head and allows no pipe-wall velocity. The downstream valve has zero mass and an elastic anchor. It closes gradually, such that the boundary conditions are (Zanganeh et al., 2015, 2019):

$$
\begin{aligned}
& \frac{V-\dot{u}_{z}}{\left(V-\dot{u}_{z}\right)_{0}}=\alpha_{v} \sqrt{\frac{\left|\Delta\left(\tilde{H}+H_{0}\right)\right|}{\left|\Delta H_{0}\right|},} \\
& \sigma_{z} A_{t}=\rho_{f} g \tilde{H} A_{f}-F_{v s} \\
& =\rho_{f} g \tilde{H} A_{f}-k_{v s} u_{z} .
\end{aligned}
$$

Eq. (B.6) is used as boundary condition in the hydraulic equations, where $\Delta H_{0}$ is the steady-state head-loss over the valve and the time-dependent parameter $\alpha_{v}$ (ranging from 0 to 1 ) defines the valve opening. Eq. (B.7), in which $\sigma_{z}$ is the axial pipe-wall stress, is the force balance at the valve; it is the boundary condition used in the numerical method for the structure. The anchor force against axial movement is $F_{v s}$ and $k_{v s}$ is the anchor stiffness; $A_{t}$ is the cross-sectional area of the pipe wall. The boundary condition for axial intermediate supports due to the force balance gives (Zanganeh et al., 2019):

$$
\left(\left(\sigma_{z}\right)_{z=z_{s}}^{R}-\left(\sigma_{z}\right)_{z=z_{s}}^{L}\right) A_{t}=k_{s} u_{z},
$$

where subscript $s$ denotes the support node, superscripts $L$ and $R$ stand for the left and right sides, and $k_{s}$ is the axial stiffness.

\section{Numerical method}

The governing equations in conjunction with the initial and boundary conditions are solved using the method of characteristics (MOC) for Eqs. (B.1) and (B.2), and the finite-element method (FEM) for Eq. (B.3). The solution process has been applied in a reservoir-pipe-valve system with elastic pipes by Lavooij and Tijsseling (1991) and with viscoelastic pipes by Keramat et al. (2012).

\section{- MOC method for hydraulic equations}

Considering $H$ and $Q$ as the dependent variables, Eqs. (B.1) and (B.2) can be transformed to two ordinary differential equations along two characteristic lines (called $\mathrm{C}^{-}$and $\mathrm{C}^{+}$) which allow to be written in finite-difference form as (Keramat et al., 2012):

$$
\begin{array}{ll}
C^{+}: & Q_{P}=\left(Q_{A_{1}}+B H_{A_{1}}+C_{p_{1}}^{\prime \prime \prime}+C_{p_{1}}^{\prime \prime \prime}\right)-\left(B+C_{p_{2}}^{\prime \prime \prime}\right) H_{P}, \quad B=g A_{f} / c_{f} \\
C^{-}: & Q_{P}=\left(Q_{A_{2}}+B H_{A_{2}}+C_{n_{1}}^{\prime \prime \prime}+C_{n_{1}}^{\prime \prime \prime}\right)+\left(B+C_{n_{2}}^{\prime \prime \prime}\right) H_{P},
\end{array}
$$

where subscript $P$ indicates unknown quantities at the current time step, the subscripts $p$ and $n$ stand for the "positive" and "negative" characteristic lines and quantities holding the index $A_{1}\left(A_{2}\right)$ correspond to points on the line $\mathrm{C}^{+}\left(\mathrm{C}^{-}\right)$at the previous time step $t-\Delta t$. Superscripts '"' and "'I' refer to pipe viscoelastic behavior and Poisson coupling, respectively. The constants $C_{p_{1}}^{\prime \prime \prime}, C_{p_{2}}^{\prime \prime \prime}, C_{p_{1}}^{\prime \prime \prime}, C_{n_{1}}^{\prime \prime \prime}, C_{n_{2}}^{\prime \prime \prime}$ and $C_{n_{1}}^{\prime \prime \prime}$ are defined as follows:

$$
\begin{aligned}
& C_{p_{1}}^{\prime \prime \prime}=-C_{n_{1}}^{\prime \prime \prime}=a_{0} a_{2}, \quad C_{p_{2}}^{\prime \prime \prime}=C_{n_{2}}^{\prime \prime \prime}=a_{0} a_{1} \quad \text { with } \\
& a_{0}=\frac{D}{e} A_{f} \rho_{f} c_{f} g\left(1-v^{2}\right) \Delta t, \quad a_{1}=-\sum_{k=1}^{N_{K V}} \frac{J_{k}}{\Delta t}\left(1-\mathrm{e}^{-\frac{\Delta t}{\tau_{k}}}\right), \\
& a_{2}=\left(H(t-\Delta t)-H_{0}\right) \sum_{k=1}^{N_{K V}}\left(\frac{J_{k}}{\tau_{k}} \mathrm{e}^{-\frac{\Delta t}{\tau_{k}}}\right)-H(t-\Delta t) \sum_{k=1}^{N_{K V}} \frac{J_{k}}{\Delta t}\left(1-\mathrm{e}^{-\frac{\Delta t}{\tau_{k}}}\right)-\sum_{k=1}^{N_{K V}} \frac{\mathrm{e}^{-\frac{\Delta t}{\tau_{k}}}}{\tau_{k}} I_{\tilde{H} k}(t-\Delta t) .
\end{aligned}
$$

and

$$
C_{p_{1}}^{\prime \prime \prime \prime}=-C_{n_{1}}^{\prime \prime \prime \prime}=2 v A_{f} c_{f} \Delta t \frac{\partial \dot{u}_{z}}{\partial z} .
$$

If the pipe-wall material is elastic, $C_{p_{1}}^{\prime \prime \prime}=C_{p_{2}}^{\prime \prime \prime}=C_{n_{1}}^{\prime \prime \prime}=C_{n_{2}}^{\prime \prime \prime}=0$. If the Poisson coupling is neglected, $C_{p_{1}}^{\prime \prime \prime \prime}=C_{n_{1}}^{\prime \prime \prime \prime}=0$.

\section{- FEM method for structural equation}

First, the weak form of Eq. (B.3) is formulated. Then, by the application of Galerkin's method and using a linear shape function $\mathbf{N}=\left\{\left(z_{b}-z\right) / l, \quad\left(z-z_{a}\right) / l\right\}^{\mathrm{T}}$, the following matrix-vector relation is obtained for a typical element $e$ located between $z=z_{a}$ and $z=z_{b}$ :

$$
\begin{aligned}
& \rho_{t}\left(1+E_{0} b_{1}\right) \mathbf{M}_{\mathbf{e}} \ddot{\mathbf{i}}+E_{0} \mathbf{K}_{\mathbf{e}} \mathbf{u}=\left(q+b_{2}\right) \mathbf{f}_{\mathbf{e}}+E_{0}\left[\mathbf{N} \frac{\partial u_{z}}{\partial z}\right]_{z_{a}}^{z_{b}}, \\
& q=\rho_{f} g \frac{v D}{2 e} \frac{\partial \tilde{H}}{\partial z}, \quad \mathbf{M}_{\mathbf{e}}=\frac{l}{6}\left[\begin{array}{ll}
2 & 1 \\
1 & 2
\end{array}\right], \quad \mathbf{K}_{\mathbf{e}}=\frac{1}{l}\left[\begin{array}{cc}
1 & -1 \\
-1 & 1
\end{array}\right], \quad \mathbf{f}_{\mathbf{e}}=\frac{l}{2}\left[\begin{array}{l}
1 \\
1
\end{array}\right],
\end{aligned}
$$


where $\mathbf{u}$ is the vector of nodal displacements of the element and $l=z_{b}-z_{a}$. The quantities $b_{1}$ and $b_{2}$ are determined as follows:

$$
\begin{aligned}
b_{1}= & \sum_{k=1}^{N_{\mathrm{KV}}}\left(J_{k}-\frac{J_{k} \tau_{k}}{\Delta t}\left(1-\mathrm{e}^{\frac{-\Delta t}{\tau_{k}}}\right)\right), \\
b_{2}= & g \rho_{f} E_{0} b_{1} \frac{v D}{2 e} \frac{\partial \tilde{H}}{\partial z}(t)+g \rho_{f} E_{0} b_{3} \frac{v D}{2 e} \frac{\partial \tilde{H}}{\partial z}(t-\Delta t)+g \rho_{f} E_{0} \frac{v D}{2 e} \sum_{k=1}^{N_{\mathrm{KV}}}\left(\mathrm{e}^{\frac{-\Delta t}{\tau_{k}}} \frac{\partial I_{\tilde{H} k}}{\partial z}(t-\Delta t)\right) \\
& \quad-\rho_{t} E_{0} b_{3} \ddot{u}_{z}(t-\Delta t)-\rho_{t} E_{0} \sum_{k=1}^{N_{\mathrm{KV}}}\left(\mathrm{e}^{\frac{-\Delta t}{\tau_{k}}} I_{\ddot{u}_{z} k}(t-\Delta t)\right), \\
b_{3}= & \sum_{k=1}^{N_{\mathrm{KV}}}\left(-J_{k} \mathrm{e}^{\frac{-\Delta t}{\tau_{k}}}+\frac{J_{k} \tau_{k}}{\Delta t}\left(1-\mathrm{e}^{\frac{-\Delta t}{\tau_{k}}}\right)\right) .
\end{aligned}
$$

For elastic pipes $b_{1}=b_{2}=0$. Eq. (B.13) is valid for both interior and boundary elements. The global mass and stiffness matrices together with the force vector of the entire system are formed for the time domain solution using the unconditionally stable Newmark- $\beta$ scheme with $\beta=1 / 4$.

- Implementation of boundary condition of support at the downstream valve node

For the valve node in the viscoelastic pipe, using Eq. (B.7), the hoop stress $\sigma_{\phi}=(D / 2 e) \rho_{f} g \tilde{H}$, and considering the junction coupling, the last expression on the right-hand side of Eq. (B.13) which concerns the element boundaries becomes (Zanganeh et al., 2019)

$$
\begin{aligned}
\left.E_{0} \frac{\partial u_{z}}{\partial z}\right|_{z_{b}=z_{v a l v e}} & =\rho_{f} g \frac{D}{2 e}\left(\frac{1}{2}-v\right)\left(\tilde{H}_{P}(t)+E_{0} I_{\tilde{H}_{P}}\right)-\frac{k_{v s}}{A_{t}}\left(u_{z P}(t)+E_{0} I_{u_{z P}}\right) \\
& \approx \rho_{f} g \frac{D}{2 e}\left(\frac{1}{2}-v\right)\left(\left(1+E_{0} b_{1}\right) \tilde{H}_{P}(t)+b_{4}\right)-\frac{k_{v s}}{A_{t}}\left(\left(1+E_{0} b_{1}\right) u_{z P}(t)+b_{5}\right),
\end{aligned}
$$

in which $b_{4}$ and $b_{5}$ are defined by

$$
\begin{aligned}
& b_{4}=b_{3} E_{0} \tilde{H}_{P}(t-\Delta t)+E_{0} \sum_{k=1}^{N_{\mathrm{KV}}}\left(\mathrm{e}^{\frac{-\Delta t}{\tau_{k}}} I_{\tilde{H}_{P} k}(t-\Delta t)\right), \\
& b_{5}=b_{3} E_{0} u_{z P}(t-\Delta t)+E_{0} \sum_{k=1}^{N_{\mathrm{KV}}}\left(\mathrm{e}^{\frac{-\Delta t}{\tau_{k}}} I_{u_{z P K}}(t-\Delta t)\right),
\end{aligned}
$$

where $b_{1}$ and $b_{3}$ are defined in Eq. (B.14). If an elastic pipe is used, $b_{1}, b_{4}$, and $b_{5}$ are set to zero.

- Implementation of boundary condition of support at interior node

When Eq. (B.13) is assembled for all elements, the last term of this equation vanishes at interior nodes without support. At interior nodes with support, the last term of Eq. (B.13) reduces to (Zanganeh et al., 2019)

$$
E_{o}\left(\frac{\partial u_{z}}{\partial z}\right)_{z=z_{s}^{R}}-E_{0}\left(\frac{\partial u_{z}}{\partial z}\right)_{z=z_{s}^{L}} \approx \frac{k_{s}}{A_{t}}\left(\left(1+E_{0} b_{1}\right) u_{z P}(t)+b_{5}\right)
$$

in which $z_{s}$ is the location of the support.

\section{Appendix C. MDOF model of the pipeline structure}

The pipe system depicted in Fig. 4 can be simulated as lumped masses vibrating axially. The system may be modeled by combinations of bar elements with stiffness $E A / L$ and elastic supports with stiffness $k^{s}$. By means of the illustrations in Fig. C.1, the nodal masses $m_{p}$ and stiffness quantities $k_{p}^{s}, p=1,2, \ldots, 298$ are

$$
\begin{aligned}
& m_{p}=0, \quad p=2,4, \ldots, 298 \\
& k_{p}^{s}=0, \quad p=1,3, \ldots, 297
\end{aligned}
$$

The system depicted in Fig. C.1 represents a MDOF system whose first node has the following equation of motion

$$
m_{1} \ddot{u}_{1}+\left(k_{1}+k_{1}^{s}+k_{2}\right) u_{1}-k_{2} u_{2}-k_{1} u_{0}=0,
$$

and the second node vibrates through

$$
m_{2} \ddot{u}_{2}+\left(k_{2}+k_{2}^{s}+k_{3}\right) u_{2}-k_{2} u_{1}-k_{3} u_{3}=0 .
$$




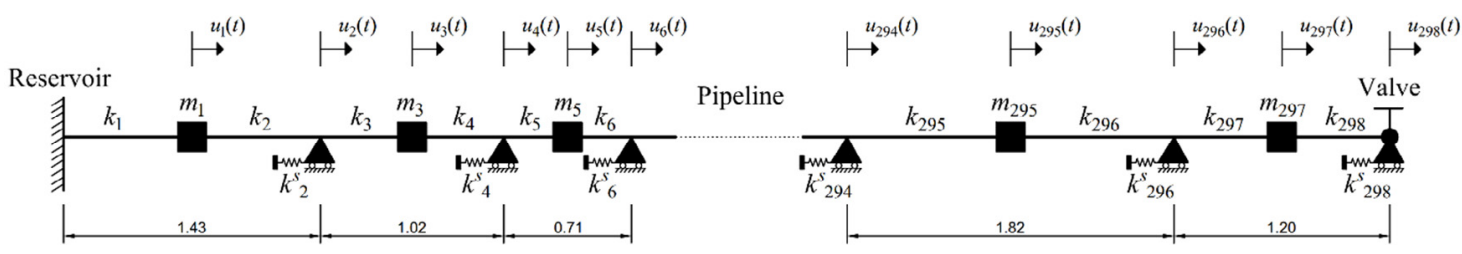

Fig. C.1. The MDOF model of the experimental pipe rig.

The two relations may be governed by the generic relation as follows

$$
m_{p} \ddot{u}_{p}+\left(k_{p}+k_{p}^{S}+k_{p+1}\right) u_{p}-k_{p+1} u_{p+1}-k_{p} u_{p-1}=0, \quad p=1,2, \ldots, 298
$$

which is valid for all nodes (masses and supports). The system of equations constructed by Eq. (C.5) can be written in matrix format

$$
\mathbf{M u ̈}+\mathbf{K u}=\mathbf{0}
$$

The system of differential equations in Eq. (C.6) can be solved by assuming the following solution corresponding to each vibrational mode $j$ and frequency $\omega_{j}$

$$
\mathbf{u}_{j}=\mathbf{U}_{j} \mathrm{e}^{\mathrm{i} \omega_{j} t}
$$

Substituting in Eq. (C.6) yields

$$
\left(-\omega_{j}^{2} \mathbf{M}+\mathbf{K}\right) \mathbf{U} \mathrm{e}^{i \omega_{j} t}=0
$$

The eigenvalue problem in Eq. (C.8) results in 297 eigenvalues $\left(\omega_{1}^{2}, \omega_{2}^{2}, \ldots, \omega_{297}^{2}\right)$ and eigenvectors corresponding to each degree of freedom. The final solution reads

$$
\mathbf{u}=\sum_{j=1}^{297} \mathbf{U}_{j} \mathrm{e}^{\mathrm{i} \omega_{j} t}
$$

in which $\mathbf{U}_{j}$ denotes the amplitude corresponding to the $j$ th frequency (or may be described as Fourier transform of $\mathbf{u}$ ). The frequency spectrum corresponding to each node specifically the last node $(i=297)$ comprises the $i$ th elements of the eigenvectors related to different frequencies. It is worth noting that the spectrum of displacement near the valve has the same pattern to that of the pressure fluctuations at the valve node.

\section{References}

Adamkowski, A., Henclik, S., Janicki, W., Lewandowski, M., 2017. The influence of pipeline support stiffness onto the water hammer run. Eur. J. Mech. B Fluids 61 (2), 297-303.

Ahmadi, A., Keramat, A., 2010. Investigation of fluid-structure interaction with various types of junction coupling. J. Fluids Struct. 26, $1123-1141$.

Clough, R.W., Penzien, J., 1993. Dynamics of Structures, second ed. McGraw-Hill, ISBN: 0-07-011394-7, p. 738.

Covas, D., Stoianov, I., Mano, J., Ramos, H., Graham, N., Maksimovic, C., 2005. The dynamic effect of pipe-wall viscoelasticity in hydraulic transients. Part II-model development, calibration and verification. J. Hydraul. Res. 43, 56-70.

Diesselhorst, T., Schmidt, R., Schnellhammer, W., 2000. Realistic calculation of pressure surges. Inclusion of dynamic friction and fluid/structure interaction. 3R Int. 39, 678-682, (in German).

Duan, H.F., Ghidaoui, M.S., Lee, P.J., Tung, Y.K., 2010. Unsteady friction and visco-elasticity in pipe fluid transients. J. Hydraul. Res. 48 (3), 354-362. Feeny, B., Guran, A., Hinrichs, N., Popp, K., 1998. A historical review on dry friction and stick-slip phenomena. Appl. Mech. Rev. 51 (5), $321-341$.

Ferrante, M., Brunone, B., 2003. Pipe system diagnosis and leak detection by unsteady-state Test-1: Harmonic Analysis. Adv. Water Resour. 26, 95-105.

Ferrante, M., Brunone, B., Meniconi, S., Karney, B.W., Massari, C., 2014. Leak size, detectability and test conditions in pressurized pipe systems: how leak size and system conditions affect the effectiveness of leak detection techniques. Water Resour. Manage. 28, 4583-4598. http://dx.doi.org/ 10.1007/s11269-014-0752-6.

Ferras, D., Manso, P.A., Schleiss, A.J., Covas, D., 2017. Fluid-structure interaction in straight pipelines with different anchoring conditions. J. Sound Vib. 394, 348-365.

Gong, J., Zecchin, A., Lambert, M., Simpson, A., 2015. Study on the frequency response function of viscoelastic pipelines using a multi-element Kevin-Voigt model. In: Proc. 13th Computer Control for Water Industry Conference, Leicester, pp. 226-234.

Hara, F., 1988. Seismic vibration analysis of fluid-structure interaction in LMFBR piping systems. ASME J. Press. Vessel Technol. 110, 177-181.

Heinsbroek, A., Tijsseling, A., 1994. The influence of support rigidity on waterhammer pressures and pipe stresses. In: Proceedings of the 2nd International Conference on Water Pipeline Systems. BHR Group, Edinburgh, Scotland, pp. 17-30.

Henclik, S., 2012. The influence of elastic pipe supports and structural damping on water hammer with fluid-structure interaction. In: Proc. 11th International Conference of Pressure Surges, Lisbon, pp. 365-379.

Henclik, S., 2018. Numerical modeling of water hammer with fluid-structure interaction in a pipeline with viscoelastic supports. J. Fluids Struct. 76, 469-487.

Keramat, A., Ghidaoui, M., Wang, X., Louati, M., 2018. Cramer-rao lower bound for performance analysis of leak detection. J. Hydraul. Eng. ASCE http: //dx.doi.org/10.1061/(ASCE)HY.1943-7900.0001603. 
Keramat, A., Haghighi, A., 2014. Transient-based approach for the creep function determination in viscoelastic pipes. J. Hydraul. Eng. ASCE 140 (12), http://dx.doi.org/10.1061/\%28ASCE\%29HY.1943-7900.0000929.

Keramat, A., Kolahi, A., Ahmadi, A., 2013. Waterhammer modelling of viscoelastic pipes with a time-dependent Poisson's ratio. J. Fluids Struct. 43, $146-178$

Keramat, A., Tijsseling, A., Hou, Q., Ahmadi, A., 2012. Fluid-structure interaction with pipe-wall viscoelasticity during water hammer. J. Fluids Struct. $28,434-455$.

Keramat, A., Wang, X., Louati, M., Meniconi, S., Brunone, B., Ghidaoui, M.S., 2019. Objective functions for transient-based pipeline leakage detection in a noisy environment: Least square and matched-filter. J. Water Resour. Plan. Manage. ASCE http://dx.doi.org/10.1061/(ASCE)WR.1943-5452. 0001108.

Keramat, A., Zanganeh, R., 2019. Statistical performance analysis of transient-based extended blockage detection in a water supply pipeline. J. Water Supply: Res. Technol.-Aqua 68 (5), 346-357.

Kwong, A., Edge, K., 1998. A method to reduce noise in hydraulic systems by optimizing pipe clamp locations. Proc. Inst. Mech. Eng. I 212 (4), $267-280$.

Lavooij, C., Tijsseling, A., 1991. Fluid-structure interaction in liquid-filled piping systems. J. Fluids Struct. 5 (5), 573-595.

Lee, P.J., Duan, H.F., Ghidaoui, M., Karney, B., 2013. Frequency domain analysis of pipe fluid transient behaviour. J. Hydraul. Res. 51, 609-622.

Lee, P.J., Duan, H., Tuck, J., Ghidaoui, M., 2015. Numerical and experimental study on the effect of signal bandwidth on pipe assessment using fluid transients. pp. 1-10. http://dx.doi.org/10.1061/(ASCE)HY.1943-7900.0000961.

Lesmez, M.W., Wiggert, D., Hatfield, F., 1990. Modal analysis of vibrations in liquid-filled piping systems. J. Fluids Eng. 112 (3), $311-318$.

Li, S., Karney, B.W., Liu, G., 2015. FSI Research in pipeline systems - A review of the literature. J. Fluids Struct. 57, 277-297. http://dx.doi.org/10. 1016/j.jfluidstructs.2015.06.020.

Liu, G., Li, Y., 2011. Vibration analysis of liquid-filled pipelines with elastic constraints. J. Sound Vib. 330 (13), 3166-3181.

Meniconi, S., Duan, H.F., Brunone, B., Ghidaoui, M.S., Lee, P.J., Ferrante, M., 2014. Further developments in rapidly decelerating turbulent pipe flow modeling. J. Hydraul. Eng. ASCE 140 (7), 04014028.

Oppenheim, A.V., Willsky, A.S., Young, I.T., 1983. Signals and Systems, fifteenth ed. Prentice-Hall, Englewood Cliffs, N.J., Chicago.

Shannon, C.E., 1949. Communication in the presence of noise. Proc. IRE 37 (1), 10-21. http://dx.doi.org/10.1109/JRPROC.1949.232969.

Tijsseling, A., 1996. Fluid-structure interaction in liquid-filled pipe systems: a review. J. Fluids Struct. 10 (2), 109-146.

Tijsseling, A., 2007. Water hammer with fluid-structure interaction in thick-walled pipes. Comput. Struct. 85 (11), $844-851$.

Tijsseling, A., Vardy, A., 1996. Axial modelling and testing of a pipe rack. In: Proceedings of the BHR group Pressure Surges conference series, vol. 19, Mechanical engineering publications limited, pp. 363-384.

Tijsseling, A., Vardy, A., 2015. What is wave speed?. In: Proc. of the 12th Int. Conf. on Pressure Surges. BHR Group, Dublin, Ireland, pp. 343-360.

Wang, X., Ghidaoui, M.S., Lin, J., 2019a. Identification of multiple leaks in pipeline III: Experimental results. Mech. Syst. Signal Process. 130, 395-408, 2019.

Wang, X., Lin, J., Keramat, A., Ghidaoui, M.S., Meniconi, S., Brunone, B., 2019b. Matched-field processing for leak localization in a viscoelastic pipe : An experimental study. Mech. Syst. Signal Process. 124, 459-478.

Wiggert, D.C., Otwell, R.S., Hatfield, F.J., 1985. The effect of elbow restraint on pressure transients. J. Fluids Eng. 107 (9), $403-406$.

Wiggert, D.C., Tijsseling, A., 2001. Fluid transients and fluid-structure interaction in flexible liquid-filled piping. Appl. Mech. Rev. 54 (9), $455-481$.

Xu, Y., Johnston, D.N., Jiao, Z., Plummer, A.R., 2014. Frequency modelling and solution of fluid-structure interaction in complex pipelines. J. Sound Vib. 333 (10), 2800-2822.

Yang, K., Li, Q., Zhang, L., 2004. Longitudinal vibration analysis of multi-span liquid-filled pipelines with rigid constraints. J. Sound Vib. 273 (1), $125-147$.

Zanganeh, R., Jabbari, E., Tijsseling, A., Keramat, A., 2019. Fluid-structure interaction in transient-based extended defect detection of pipe walls. J. Hydraul. Eng. ASCE http://dx.doi.org/10.1061/(ASCE)HY.1943-7900.0001693.

Zanganeh, R., Keramat, A., Ahmadi, A., 2015. Fluid-structure interaction with viscoelastic support during waterhammer in a pipeline. J. Fluids Struct. $54,215-234$.

Zhang, L., Tijsseling, A., Vardy, A.E., 1999. FSI analysis of liquid-filled pipes. J. Sound Vib. 224 (1), 69-99. 